\title{
ВMJ Global Health Psychosocial influences on help-seeking behaviour for cancer in low-income and lower middle-income countries: a mixed-methods systematic review
}

\author{
Grace McCutchan (D) ,1,2 Bahr Weiss (D) , ${ }^{3}$ Harriet Quinn-Scoggins, ${ }^{1,4}$ Anh Dao, ${ }^{3}$ \\ Tom Downs, ${ }^{5}$ Yunfeng Deng, ${ }^{3} \mathrm{Ha} \mathrm{Ho},{ }^{6}$ Lam Trung, ${ }^{7}$ Jon Emery, ${ }^{8}$ Kate Brain ${ }^{1}$
}

To cite: McCutchan G, Weiss B, Quinn-Scoggins $\mathrm{H}$, et al. Psychosocial influences on help-seeking behaviour for cancer in low-income and lower middle-income countries: a mixed-methods systematic review. BMJ Global Health 2021;6:e004213. doi:10.1136/ bmjgh-2020-004213

Handling editor Seye Abimbola

- Prepublication history and additional material is published online only. To view please visit the journal online (http://dx. doi.org/10.1136/bmjgh-2020004213).

Received 15 October 2020 Revised 9 December 2020 Accepted 6 January 2021

Check for updates

(c) Author(s) (or their employer(s)) 2021. Re-use permitted under CC BY-NC. No commercial re-use. See rights and permissions. Published by BMJ.

For numbered affiliations see end of article.

Correspondence to Dr Grace McCutchan; mccutchanGM@cardiff.ac.uk

\section{ABSTRACT}

Introduction Starting cancer treatment early can improve outcomes. Psychosocial factors influencing patients' medical help-seeking decisions may be particularly important in low and lower middle-income countries (LMIC) where cancer outcomes are poor. Comprehensive review evidence is needed to understand the psychosocial influences on medical help-seeking for cancer symptoms, attendance for diagnosis and starting cancer treatment.

Methods Mixed-methods systematic review registered on PROSPERO (CRD42018099057). Peer-reviewed databases were searched until April 2020 for studies assessing patient-related barriers and facilitators to medical helpseeking for cancer symptoms, diagnosis and treatment in adults (18+ years) living in LMICs. Quality of included studies was assessed using the Critical Appraisal Skills Programme tool. Data were synthesised using metaanalytic techniques, meta-ethnography or narrative synthesis as appropriate.

Results Of 3963 studies identified, 64 were included. In quantitative studies, use of traditional, complementary and alternative medicine (TCAM) was associated with 3.60 higher odds of prolonged medical help-seeking (95\% Cl 2.06 to 5.14). Qualitative studies suggested that use of TCAM was a key barrier to medical help-seeking in LMICs, and was influenced by causal beliefs, cultural norms and a preference to avoid biomedical treatment. Women face particular barriers, such as needing family permission for help-seeking, and higher stigma for cancer treatment. Additional psychosocial barriers included: shame and stigma associated with cancer such as fear of social rejection (eg, divorce/disownment); limited knowledge of cancer and associated symptoms; and financial and access barriers associated with travel and appointments.

Conclusion Due to variable quality of studies, future evaluations would benefit from using validated measures and robust study designs. The use of TCAM and gender influences appear to be important barriers to help-seeking in LMIC. Cancer awareness campaigns developed with LMIC communities need to address cultural influences on medical help-seeking behaviour.

\section{Key questions}

What is already known?

- Most reviews/studies of influences on medical helpseeking for cancer have focused on high-income countries (HIC), and report barriers such as low cancer awareness and negative beliefs about cancer.

- Most relevant reviews that included studies only conducted in low and lower middle-income countries (LMICs) $(n=3)$ and reviews with a global focus including studies conducted in both LMICs and HICs $(n=4)$ focused on specific tumour sites and/or synthesised their data narratively.

- No mixed-methods systematic reviews with metaanalysis and meta-ethnography have been conducted to explore the patient-related psychosocial influences on medical help-seeking for cancer symptoms, attendance for diagnosis or the start of treatment in LMICs.

What are the new findings?

- We found a relatively high prevalence of use of traditional, complementary and alternative medicine (TCAM) which was associated with prolonged help-seeking.

- Women faced particularly high levels of barriers such as needing family permission to seek medica help, and gender-related stigma (eg, for breast cancer treatment)

- Our review also identified critical research design limitations reducing the utility of the literature (eg, use of different time lengths to define 'delay' in cancer help-seeking).

\section{INTRODUCTION}

Early cancer diagnosis and treatment are key to effective and efficient treatment. ${ }^{1}$ Cancer disproportionately affects low and lower middle-income countries (LMIC) with rapidly increasing incidence ${ }^{2}$ and poorer survival ${ }^{1}$ when compared with high-income countries (HIC). Earlier stage cancer at diagnosis has a significant impact on survival, particularly 


\section{Key questions}

What do the new findings imply?

- Many studies used non-standardised measures/designs, increasing the difficulty integrating findings across studies.

- Future evaluations should use robust study designs and validated measures that have been translated and pilot tested.

- Our results suggest that barriers such as low symptom knowledge and negative beliefs about cancer may be universal barriers to helpseeking, whereas the use of TCAM and female-specific barriers to medical help-seeking may be more prevalent in LMICs.

- Our findings provide a basis for development of interventions to encourage medical help-seeking in the earlier, more treatable cancer stages to reduce the burden of cancer in LMICs.

in LMICs where advanced technology critical for treatment at later cancer stages is generally less available. ${ }^{34}$ One factor related to access to early treatment is prompt medical help-seeking for potential cancer symptoms. ${ }^{5}$ Early cancer detection and treatment are seen by the WHO as major public health and economic issues. ${ }^{6}$

Following the Aarhus statement, ${ }^{78}$ the cancer early diagnosis field has moved from describing the medical help-seeking process in terms of 'patient delay', with its connotations of blame, to using time intervals as set out in the Model of Pathways to Treatment $\left(\mathrm{MPT}^{9}\right.$; eg, 'patient interval'). The MPT describes processes underlying medical help-seeking for cancer symptoms and accessing treatment. The model delineates the time between a person first noticing a change in their body and the beginning of cancer treatment into four intervals (figure $1^{910}$ ): (1) the appraisal interval (from noticing a bodily change to perceiving a reason to seek help); (2) the help-seeking interval (from perceiving a reason to seek help to first contact with the medical professional); (3) the diagnostic interval (from first contact with the healthcare professional to diagnosis of cancer); (4) the pretreatment interval (from formal diagnosis to the start of cancer treatment). The patient interval combines both the appraisal and help-seeking intervals. In the current article we refer to longer and shorter intervals for the patient (medical help-seeking for cancer symptoms), diagnostic and pretreatment intervals (attendance for investigations or starting treatment). Although the MPT was designed to be applicable globally, ${ }^{9}$ there are few examples of the model being applied to LMIC contexts. ${ }^{11-13}$

Most research on cancer symptom appraisal and helpseeking has been conducted in HIC. In two previous systematic reviews of psychosocial influences on helpseeking for cancer symptoms, only $10 \%^{14}$ and $15 \%{ }^{15}$ of studies were conducted in LMICs. Previous systematic reviews conducted in LMICs have focused on understanding barriers to help-seeking for breast or head and neck cancer using narrative data synthesis. ${ }^{16-19}$ To date, no mixed-methods systematic review has investigated patient-related influences on medical help-seeking for cancer symptoms, attendance for examination or the start of cancer treatment in LMICs. Review of existing evidence regarding the psychosocial influences on cancer help-seeking in LMICs is essential, in order to develop effective interventions to facilitate earlier diagnosis and treatment. ${ }^{16}$

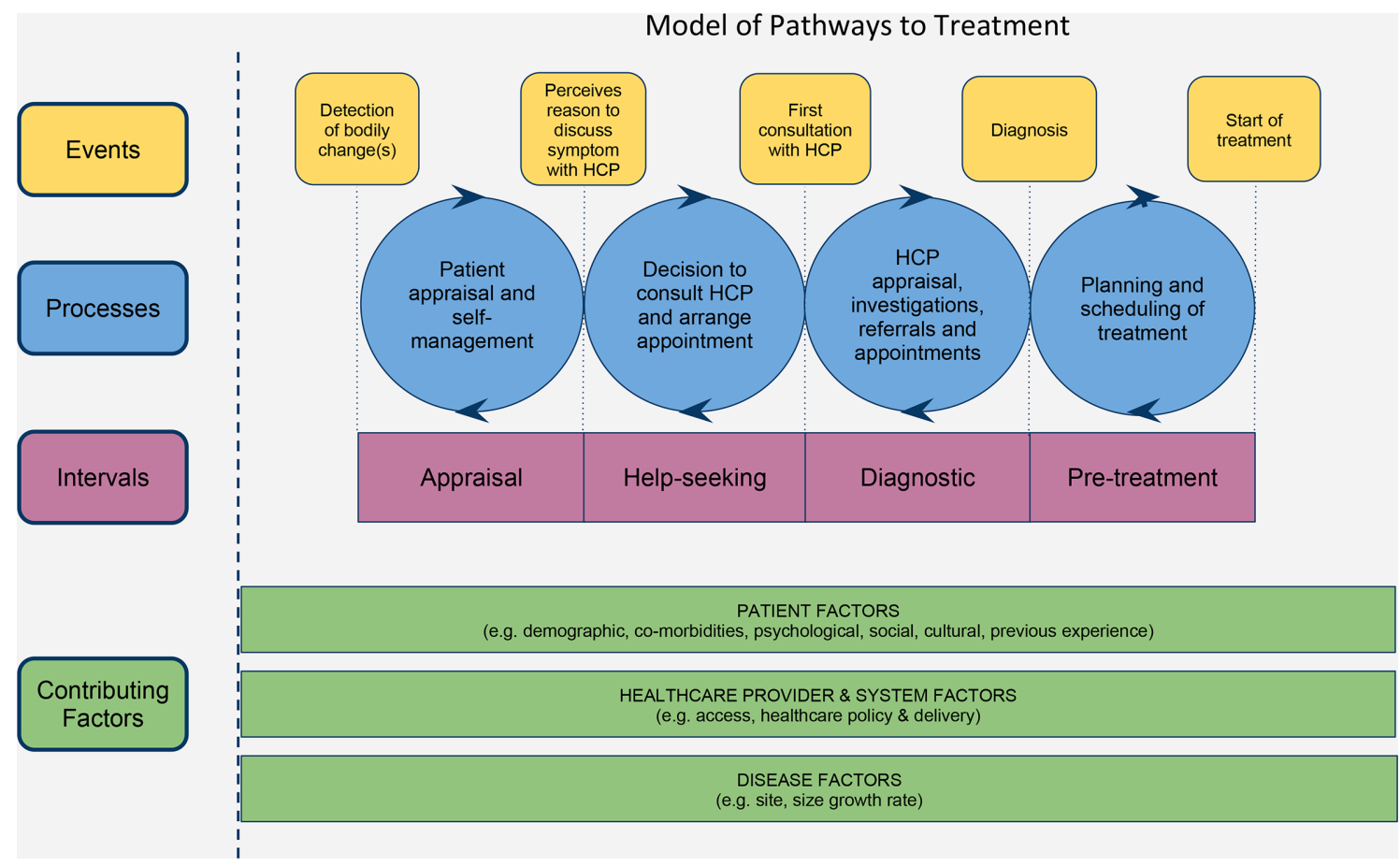

Figure 1 Model of Pathways to Treatment. HCP, healthcare professional. Reprinted with permission from Walter F, Webster A, Scott S, et al. The Andersen model of total patient delay: a systematic review of its application in cancer diagnosis. $J$ Health Serv Res Policy 2012;17:110-8. 
How patients appraise and act on potential cancer symptoms varies by tumour site and symptom type. ${ }^{20}{ }^{21}$ The current systematic review therefore included all cancer types to examine the patient-related psychosocial influences on help-seeking for cancer during the patient interval and decisions to attend healthcare during the diagnostic and pretreatment intervals in LMICs. Diverse study designs were included to identify predictors of helpseeking using meta-analytic techniques for the quantitative studies, and to gain an in-depth understanding of barriers and facilitators to help-seeking through a metaethnography $^{22}$ of qualitative studies. Quantitative data were analysed narratively to identify barriers and facilitators, including data not able to be included in the metaanalysis, to ensure results were comprehensive. Data were synthesised to form overarching conclusions and recommendations.

\section{METHODS}

This systematic review was conducted and reported in accordance with the Preferred Reporting Items for Systematic Reviews and Meta-Analyses guidelines ${ }^{23}$ (online supplemental file 1).

\section{Search strategy and selection criteria}

We conducted a mixed-methods systematic review of qualitative, quantitative and mixed-methods studies to explore patient-related barriers and facilitators to medical help-seeking behaviour for cancer symptoms and decisions to attend healthcare for diagnosis and start of cancer treatment. The review protocol was registered with the International Prospective Register of Systematic Reviews (PROSPERO) prior to study selection (https:// www.crd.york.ac.uk/prospero/display_record.php? RecordID=99057).

\section{Inclusion criteria}

Studies written in English that assessed (A) patientrelated (B) barriers/facilitators to medical help-seeking for cancer symptoms, diagnosis and the start of treatment (C) in adults (18+ years) (D) living in LMICs were included. LMIC was defined as low-income or lower middle-income countries as classified by the World Bank (https://datahelpdesk.worldbank.org/knowledgebase/articles/906519-world-bank-country-and-lendinggroups), correct at the time of protocol development (May 2018). There were no limits on date of publication or study methodology. Study designs that assessed and reported observed help-seeking behaviour (retrospectively reported actual help-seeking behaviour in patients with cancer or symptomatic participants) or hypothetical help-seeking behaviour (anticipated help-seeking in asymptomatic community or population samples) were included.

Qualitative studies that did not include time to helpseeking but where participants described their reasons for longer patient, diagnostic or pretreatment intervals were included. Included studies were required to report the contribution of one or more of the following influences on help-seeking: symptom knowledge, symptom interpretation, social influences, use of traditional or complementary medicine, cancer beliefs, competing priorities, expectations/beliefs about care seeking, availability and access to care, financial barriers, understanding/navigating the health system, cultural barriers and cancer treatment beliefs. Variables were selected based on our previous review ${ }^{15}$ and extensive scoping searches.

\section{Exclusion criteria}

Studies that were not about cancer and/or were conducted in high-income or upper middle-income economy countries were excluded. Studies that were not written in English, review papers, policy documents and conference abstracts were excluded, although relevant review papers were reviewed to identify studies for potential inclusion. Studies were excluded if they did not focus on (1) barriers to cancer help-seeking, (2) adult participants' perspectives, or were (3) low-quality studies ${ }^{24}$ as evaluated by the Critical Appraisal Skills Programme (CASP) tool.

\section{Search strategy}

Peer-reviewed literature in the electronic databases of Cochrane Library, MEDLINE (1946-2020), Global Health (1910-2020) and PsycINFO (1806-2020) was searched by TD and GMC up to April 2020. Initial searches were conducted in May 2018, and updated in June 2019 and April 2020. A comprehensive search strategy was developed by the study team and a subject librarian with expertise in literature searching ${ }^{24}$ to retrieve all studies relevant to the research question. Search terms relating to LMICs, symptomatic help-seeking, decisions to initiate treatment, cancer and barriers to help-seeking were used to search for relevant studies (online supplemental file 2 for full list of terms). Study authors were emailed by BW if additional information was required.

Titles and abstracts of studies were reviewed against the inclusion and exclusion criteria by TD and GMC. Full texts of included studies were reviewed for inclusion or exclusion by TD and GMC (figure 2). Reference lists of included studies were checked manually by GMC for additional studies. Ten per cent of studies at each stage were independently reviewed for inclusion by GMC, HQS and $\mathrm{KB}$, with good agreement $(93 \%)$. All discrepancies were resolved through discussion.

\section{Data analysis}

Data were analysed using a parallel results convergent design, ${ }^{25}$ where qualitative and quantitative findings were analysed separately and integrated in the discussion.

\section{Data extraction}

Data from all included studies were extracted onto an Excel sheet (online supplemental file 3 for full list of extracted variables). Country classifications by income group were determined by data collection year and the World Bank (https://datahelpdesk.worldbank.org/ 


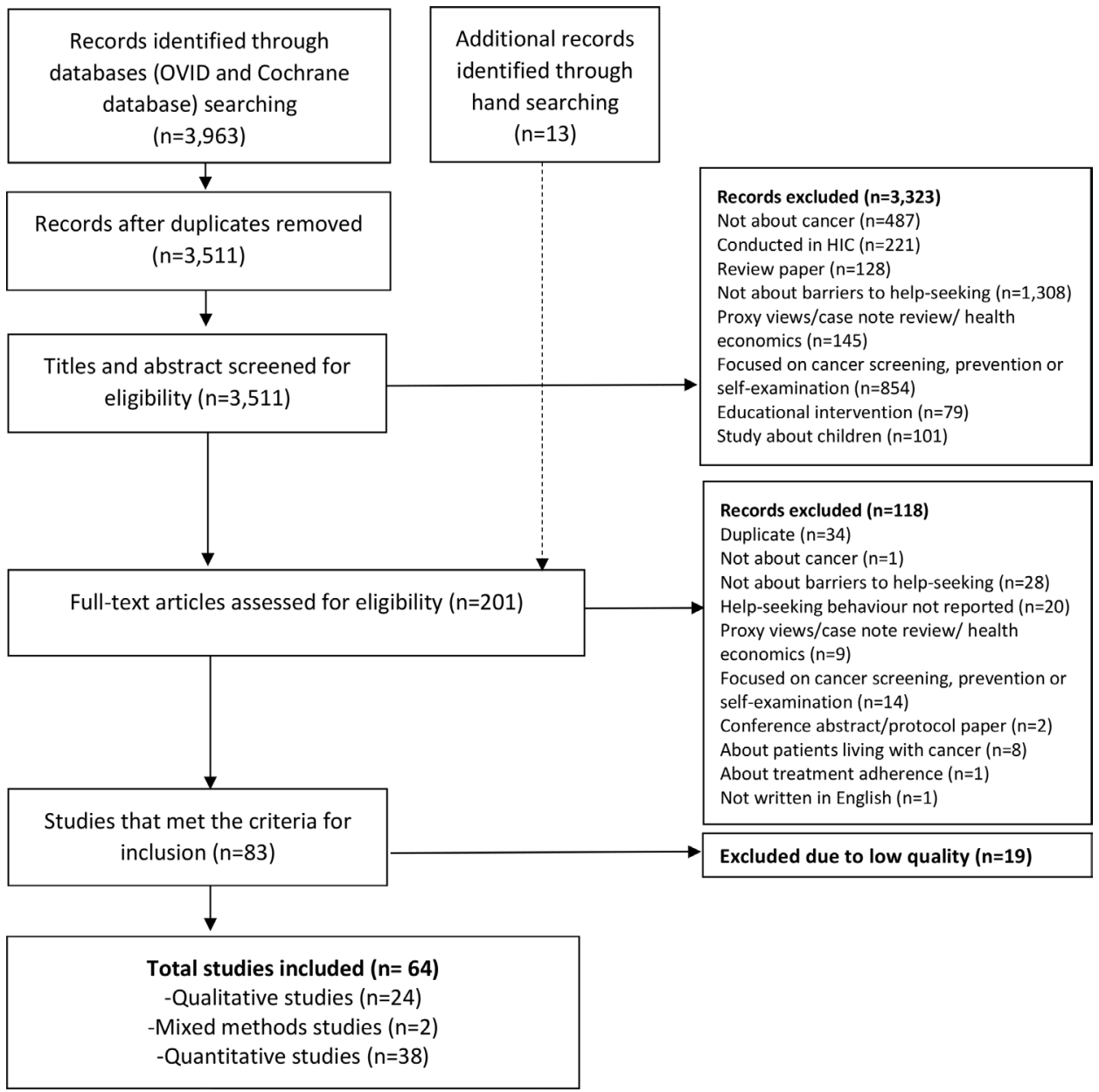

Figure 2 Preferred Reporting Items for Systematic Reviews and Meta-Analyses (PRISMA) flow chart of study selection. HIC, high-income countries.

knowledgebase/articles/906519-world-bank-countryand-lending-groups).

\section{Quality appraisal}

The CASP (www.casp-uk.net) tools were used to assess quality of studies in the following domains: validity of results, research design, participant recruitment, data collection, ethical issues, data analysis and reporting, and consideration of the contribution of their research. The tools were adapted to include questions to assess the quality of the patient interval. ${ }^{78}$ When assessing the quality of the reported patient interval the following were considered: the length of time from cancer diagnosis to data collection; whether self-report patient interval data were triangulated with medical records; how the patient/diagnosis/pretreatment interval was classified and how the patient interval was analysed. ${ }^{78}$ Quality was rated as low, medium or high. Low-quality studies were excluded. The main reasons for exclusion included insufficient information provided about data collection procedures $(n=18)$, or where intervals were measured but not reported or defined $(n=7)$.

\section{Quantitative summarisation}

All included quantitative studies were discussed in detail during team meetings (BW, GMC, AD, YD, HH). Due to the high level of heterogeneity in study measures and research designs within the context of relatively few studies, a formal meta-analysis was not feasible for most variables. However, meta-analytic techniques were used to quantitatively summarise study results regarding use of traditional, complementary and alternative medicine (TCAM) (eg, traditional healers, herbal medication, prayer camps, spiritual healers) as a predictor of helpseeking in the patient interval because TCAM use was consistently reported between studies and a high proportion of quantitative studies reported TCAM use. We first summarised the proportion of research participants who used TCAM in the patient interval, weighting studies by the square root of their sample size (proportional to the inverse of the SE for that sample's parameter estimate). We then assessed the proportion of participants who experienced significantly longer patient intervals, defined as a patient interval of 3 months or longer. Third, we summarised within-study statistics of relations between TCAM use and the probability of a longer patient interval. We extracted from the report (or computed if not reported) the OR for the effect of TCAM on 'delay', calculated as the odds of having a longer patient interval if a participant had used TCAM, over the odds of having a longer 
Table 1 Noblit and Hare's seven-stage meta-ethnographic approach

\section{Stages in Noblit and Hare 22

1. Development of the
research question

2. Scope of synthesis

\section{Activity}

Align with the overarching research question of the review: 'What are the patient-reported influences on medical help seeking in the patient, diagnostic and pre-treatment intervals in LMICs?'.

Define scope of the meta-ethnography to align with the overarching scope of the review: (1) focus on medium and high-quality studies; (2) focus on data related to patient-reported influences on medical help-seeking in the patient, diagnostic and pretreatment intervals; (3) do not include data from proxies (eg, spouses, children healthcare professionals) due to the focus on patient-reported influences.

\begin{tabular}{ll}
\hline 3. Develop main concepts & $\begin{array}{l}\text { Familiarisation with studies. Develop main concept grid with main and subconcepts and } \\
\text { description. Refine main concept grid. }\end{array}$ \\
$\begin{array}{ll}\text { 4. Determine how studies are } \\
\text { related }\end{array}$ & $\begin{array}{l}\text { Extract and separate first-order data (participant quotes) and second-order data (authors' } \\
\text { narrative interpretations) from included studies into NVivo (GMC). Code data under each of the } \\
\text { main concepts (GMC). Dual code at least 20\% of included studies (HQS and KB). Discuss and } \\
\text { resolve discrepancies in coding (GMC, KB, HQS). }\end{array}$ \\
\hline 5. Translate studies & $\begin{array}{l}\text { Create a matrix on Excel to summarise study characteristics, first and second-order data } \\
\text { under each of the main concepts and subconcepts (GMC). }\end{array}$ \\
6. Synthesise translations & $\begin{array}{l}\text { Three researchers (GMC, KB, HQS) to independently review the main concept matrix of } \\
\text { included first and second-order data to generate an overarching summary of each main }\end{array}$ \\
& $\begin{array}{l}\text { concept (third-order data). Workshop-style analysis meeting to discuss how studies relate, } \\
\text { and to identify areas of accordance and discordance. Discuss overall interpretations and } \\
\text { conclusions and how main concepts relate with one another. }\end{array}$ \\
Express the synthesis through dissemination.
\end{tabular}

LMICs, low and lower middle-income countries.

patient interval given a participant had not used TCAM. The mean OR, weighted by the square root of each study's sample size, was computed. Subgroup analyses were conducted for TCAM use as a function of the region in which the studies were conducted (Africa vs Asia) and type of cancer (breast cancer vs non-breast cancer). All other quantitative data were analysed narratively. ${ }^{26}$

\section{Qualitative summarisation}

Qualitative data from all qualitative and mixed-methods studies were synthesised using Noblit and Hare's ${ }^{22}$ sevenstage meta-ethnographic approach (table 1). Metaethnography reporting guidance ${ }^{27}$ was used.

\section{Patient and public involvement}

Patients and public were not directly involved in this review.

\section{RESULTS}

Of the 3511 studies screened for inclusion in the review, 64 met the inclusion criteria (figure 2).

As shown in table 2, data were collected using quantitative survey methods $(n=38)$, qualitative interviews or focus groups $(n=24)$ and mixed-methods $(n=2)$ to assess observed $(n=46)$, hypothetical $(n=16)$ and both observed and hypothetical $(n=2)$ help-seeking behaviours.

Thirty-five studies were conducted in sub-Saharan Africa (Uganda, $\mathrm{n}=7$; Nigeria, $\mathrm{n}=6$; Ghana, $\mathrm{n}=5$; Ethiopia, n=4; Kenya, n=3; Mali, n=2; multiple countries, $n=2$; Cameroon, n=2; Rwanda, n=1; Burkina Faso, n=1; Malawi, $\mathrm{n}=1$; Sudan, $\mathrm{n}=1$ ). Fourteen studies were conducted in South Asia (India, $\mathrm{n}=6$; Pakistan, $\mathrm{n}=5$; Bangladesh, $\mathrm{n}=2$; Nepal, $\mathrm{n}=1$ ). Ten studies were conducted in the Middle East and North Africa (Jordan, n=5; Egypt, n=4; Morocco, n=1). Four studies were conducted in East Asia and Pacific (Indonesia, $n=4$ ). One study was conducted in Latin America and Caribbean (Haiti, $\mathrm{n}=1$ ).

Most studies focused on breast cancer $(n=44)$. The remaining 20 studies focused on the following cancer sites: colorectal $(n=3)$, multiple sites $(n=6)$, cervical $(n=4)$, oral $(n=2)$, ovarian $(n=1)$, prostate $(n=1)$, lung $(n=1)$, nasopharyngeal carcinoma $(n=1)$ and Kaposi carcinoma $(n=1)$. Studies focused on the patient interval $(n=54)$, diagnostic interval $(n=10)$ and pretreatment interval $(\mathrm{n}=21)$.

Of the included studies, 11 were high quality and 53 were medium quality.

\section{Quantitative studies}

TCAM. Frequency of TCAM use in the patient interval was reported in 11 studies ( $n=2415$ participants; 10 breast cancer studies, 1 non-breast cancer study), and the mean proportion of TCAM use across the studies was 0.20 (95\% CI 0.09 to 0.31$) \cdot{ }^{28-38}$ The mean proportion of TCAM use in the patient interval in African studies $(\mathrm{n}=7)$ was $0.23(95 \%$ CI 0.07 to 0.40$)$, and $0.17(95 \%$ CI -0.08 to 0.42$)$ in Asian studies $(n=4)$. Five studies ( $\mathrm{n}=953$ participants; 4 African studies, 1 Asian study) assessed the association between TCAM use and a longer patient interval, with a mean OR of 3.60 (95\% CI 2.06 


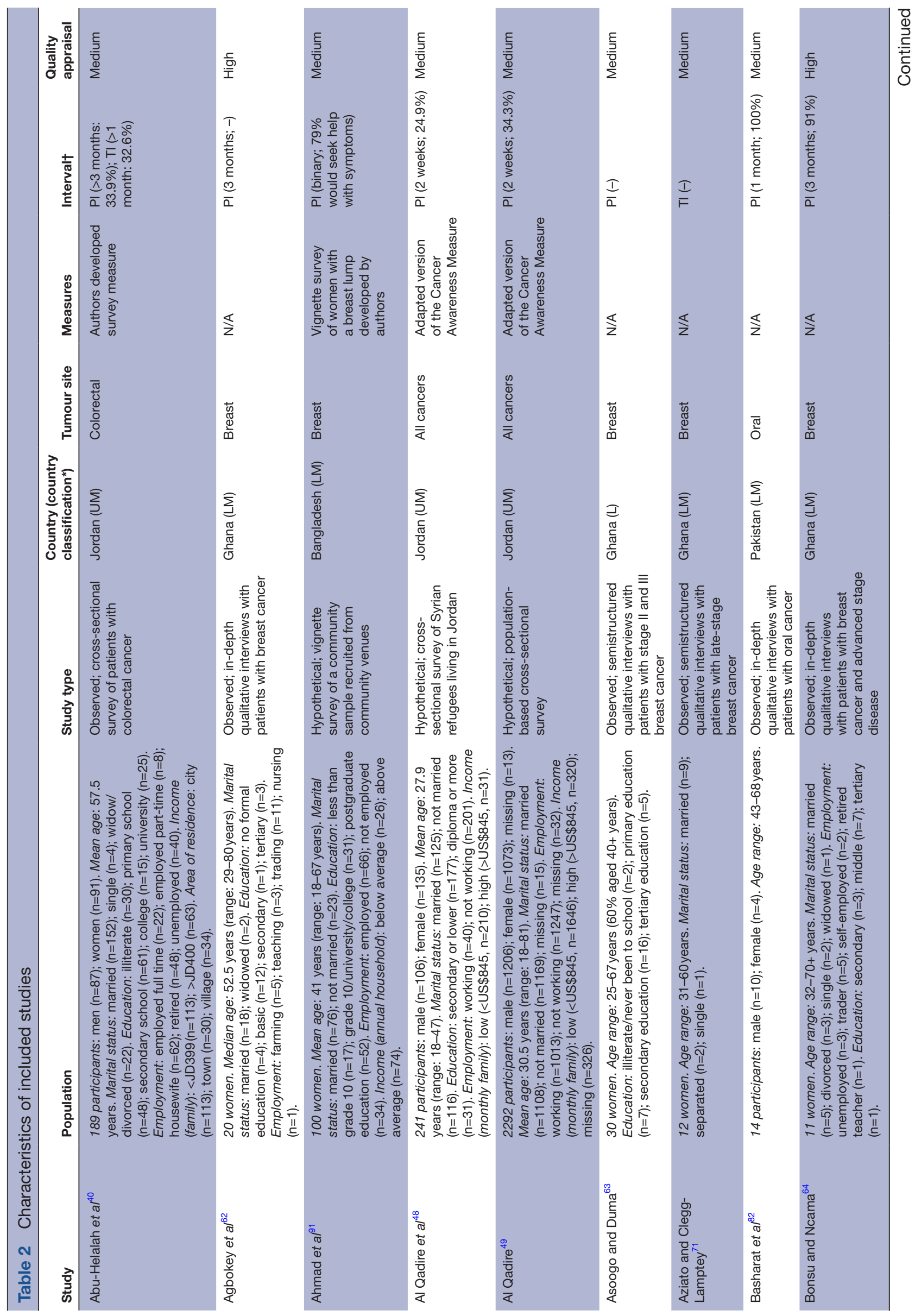

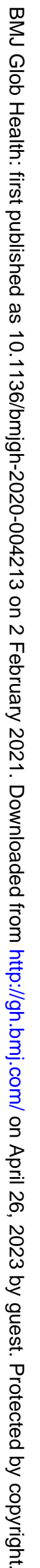




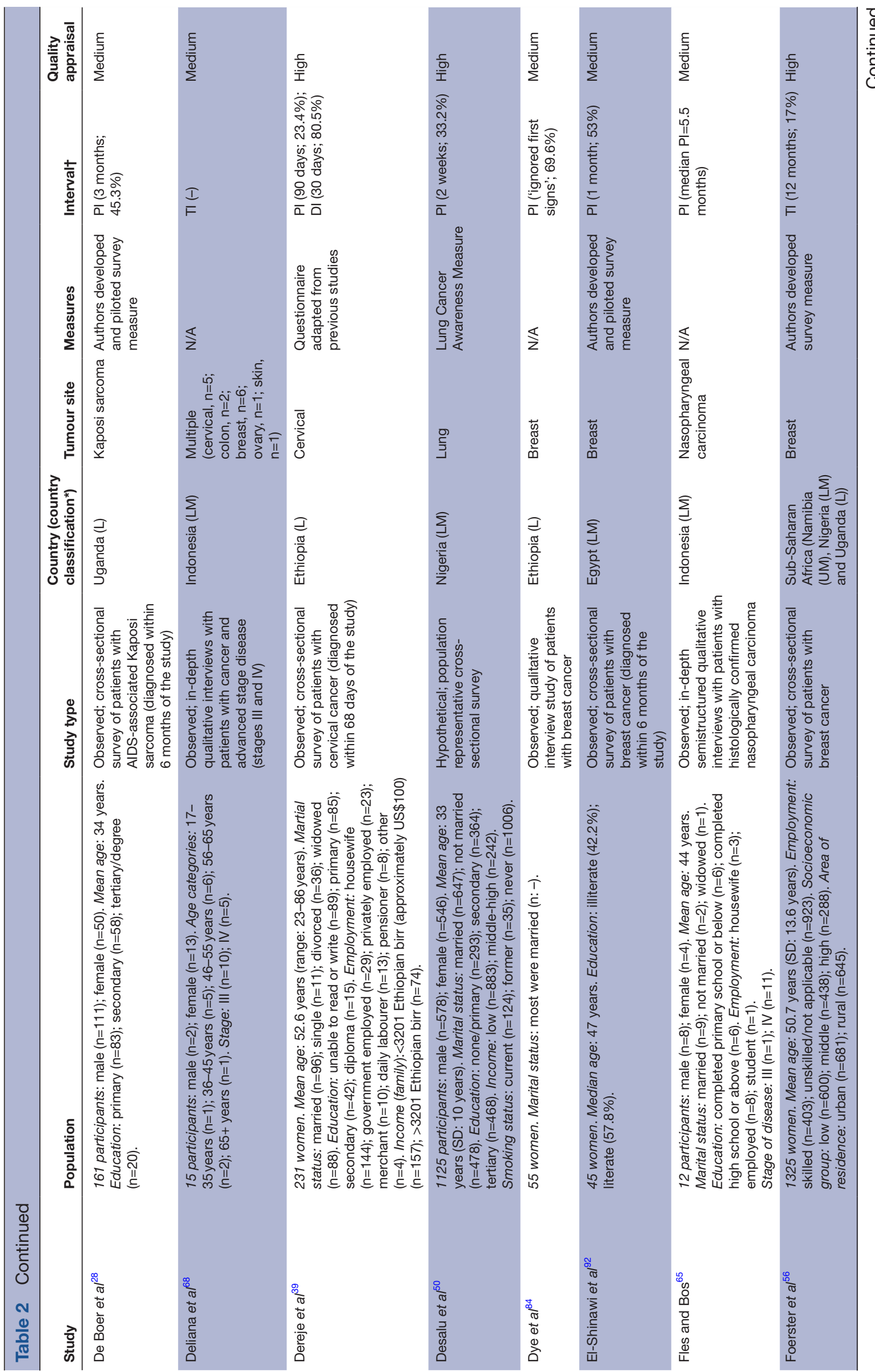




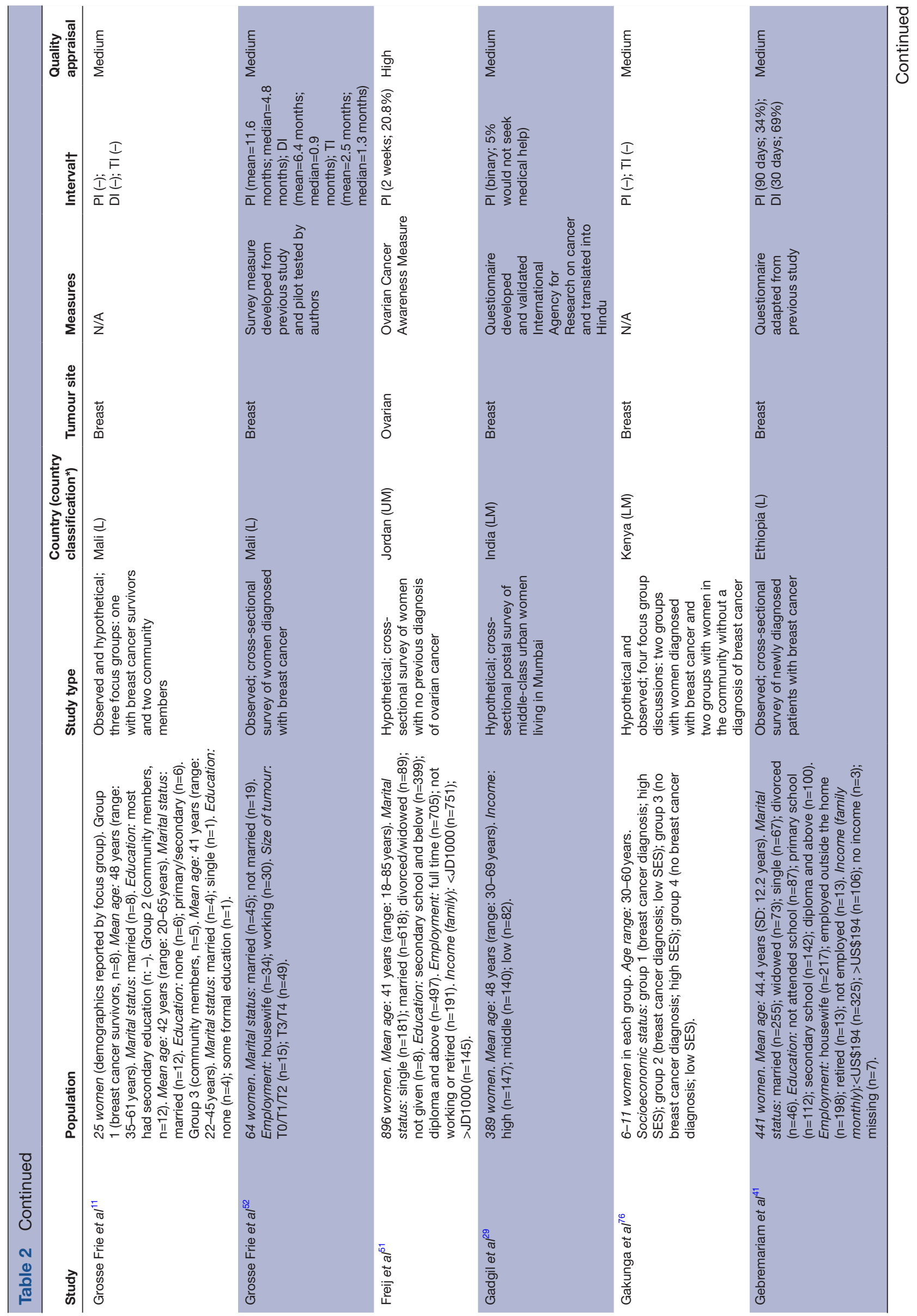

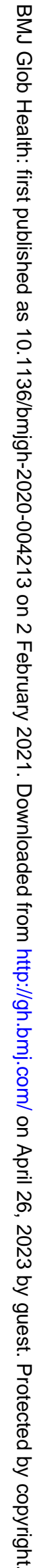




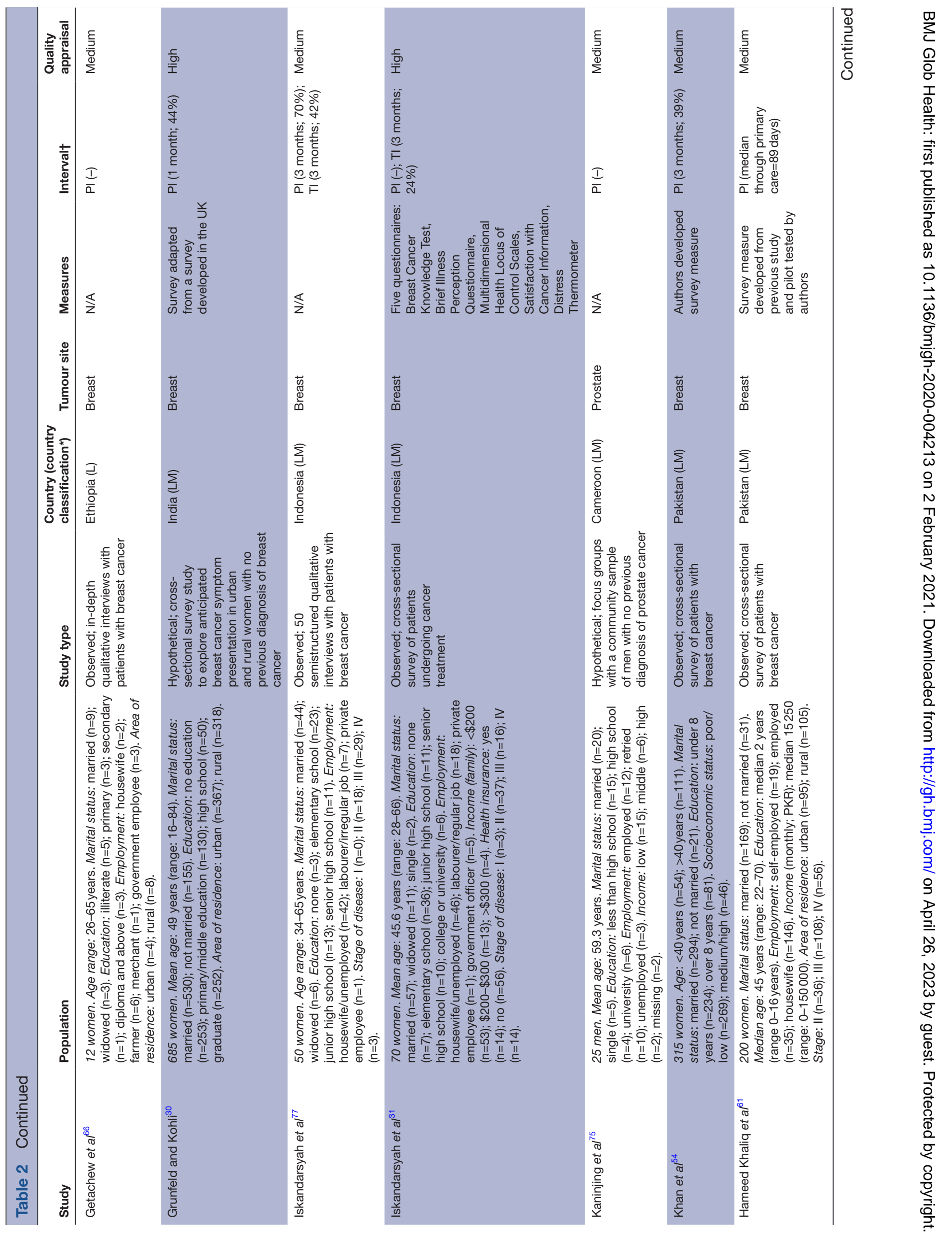




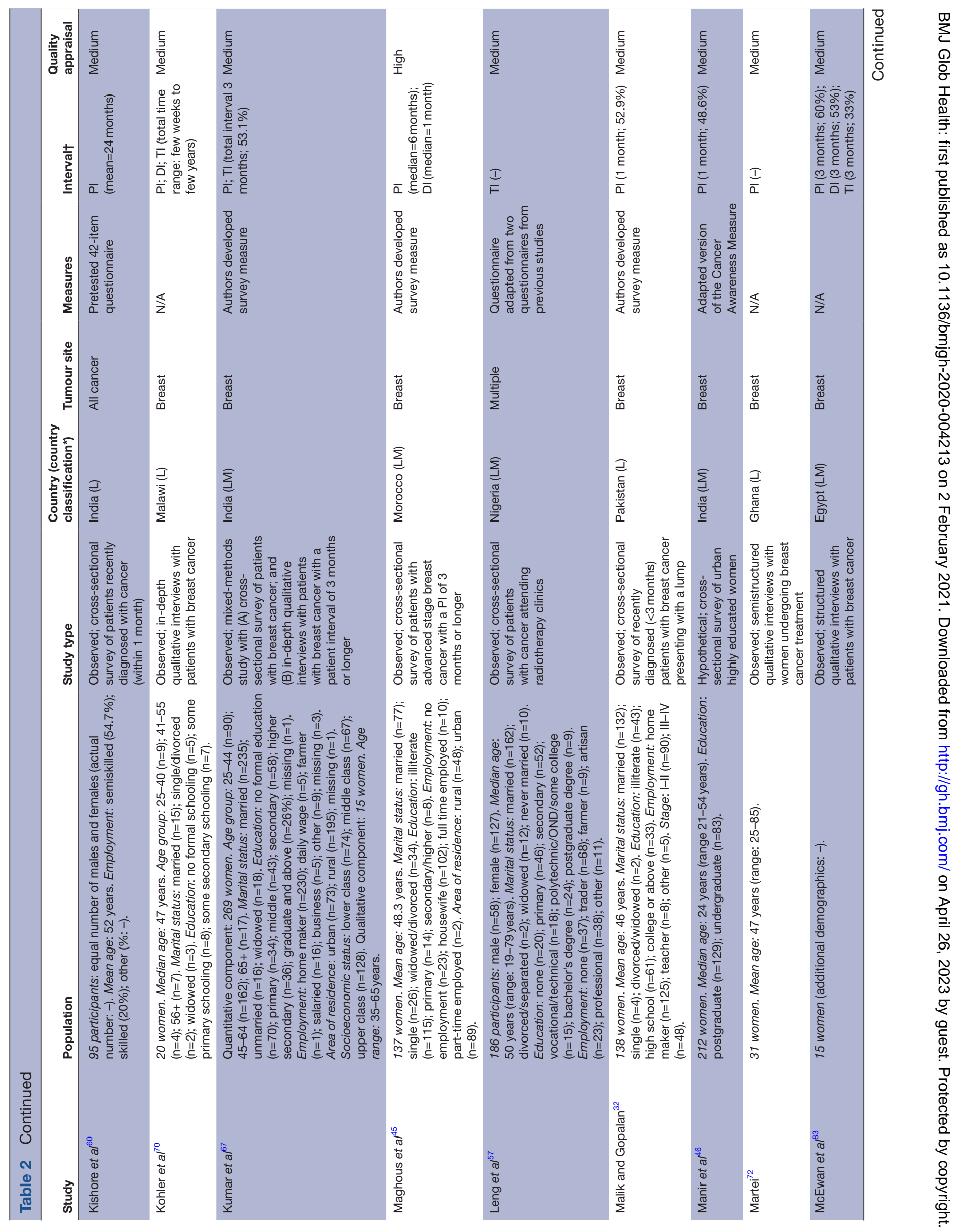




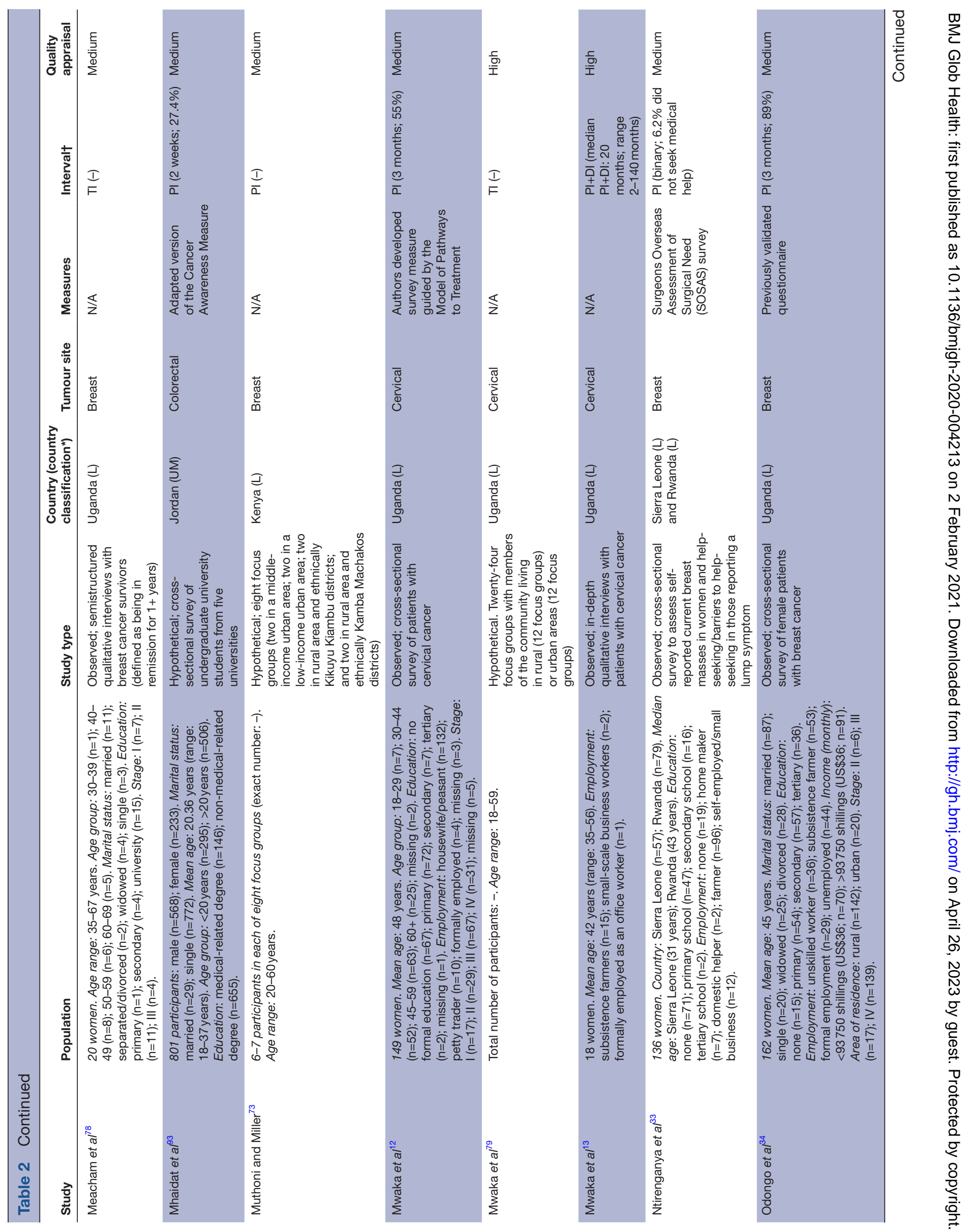




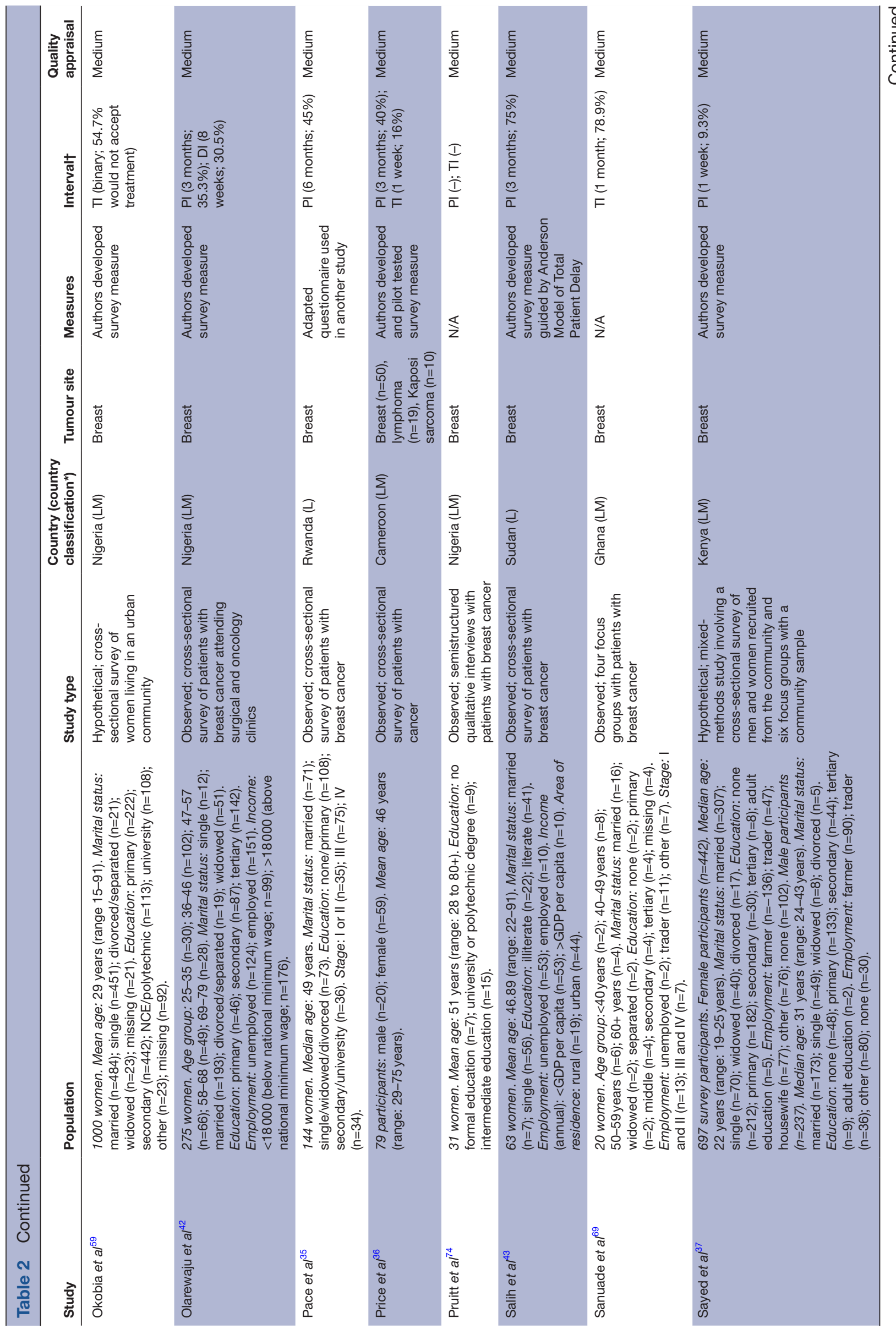




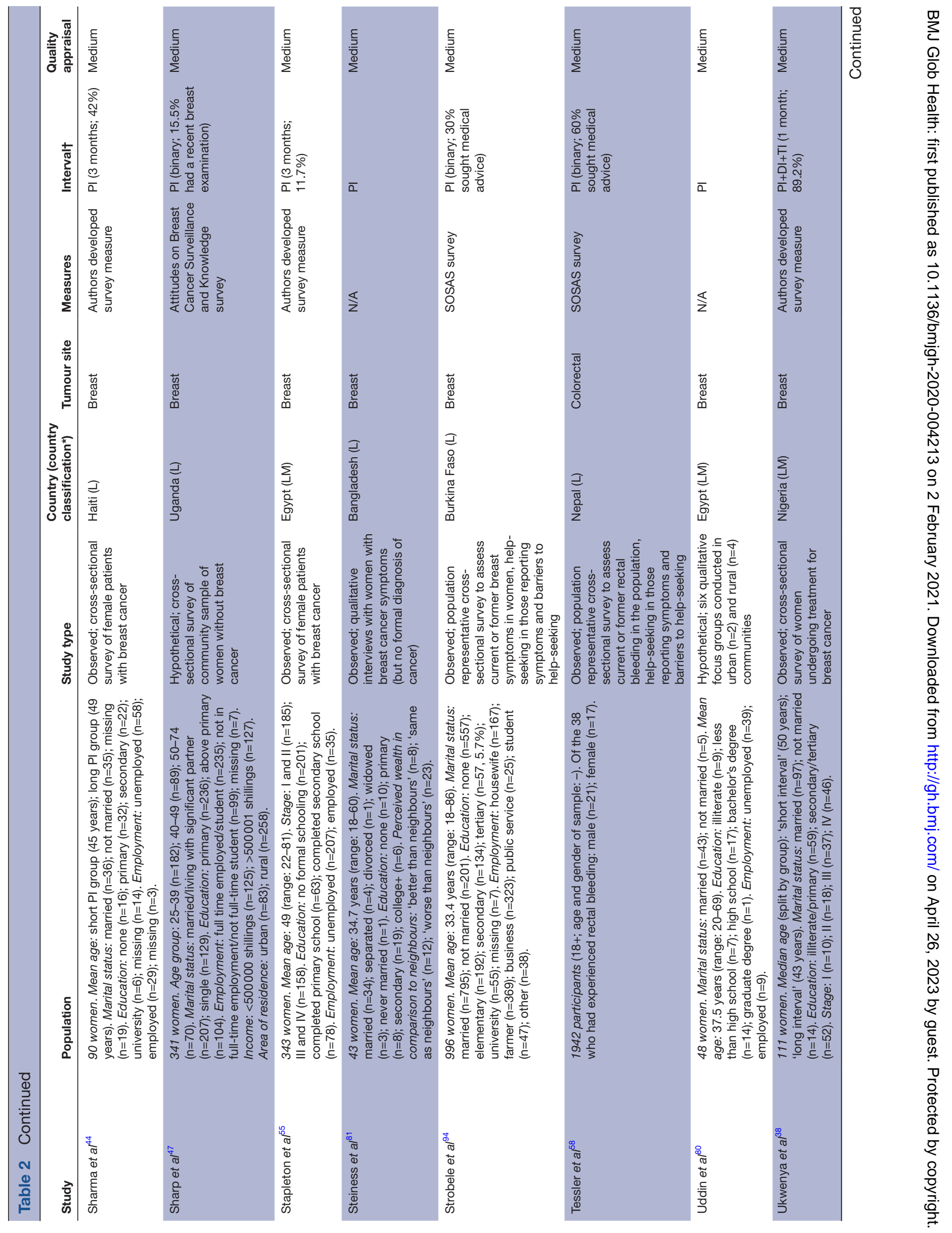




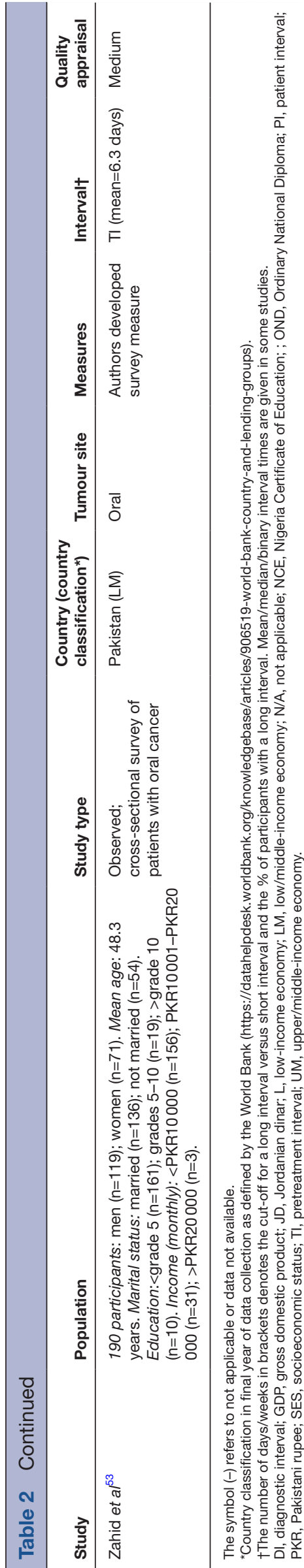

to 5.14). ${ }^{28} 32343539$ The mean OR was 4.32 (95\% CI 1.54 to 7.11$)$ for breast cancer studies $(\mathrm{n}=3)$ and $2.58(95 \%$ CI 1.39 to 3.77) for non-breast cancer studies $(n=2)$. Nine studies (eight African studies, one Asian study) assessed the proportion of participants who used TCAM who also had patient intervals greater than 3 months, with the mean proportion equal to 0.45 (95\% CI 0.29 to 0.61$).{ }^{28343639-44}$ The proportion of participants who used TCAM who had patient intervals longer than 3 months was 0.51 (95\% CI 0.27 to 0.76$)$ in breast cancer studies $(\mathrm{n}=6)$ and 0.33 (95\% CI 0.06 to 0.60$)$ in nonbreast cancer studies $(n=3)$.

Gender roles. In five female-only observed studies of patients with breast cancer, competing priorities such as housework or childcare were reported as a barrier in the patient interval in Pakistan ${ }^{32}$ and in African countries $^{35414245}$ (table 3). In three breast cancer studies, women reported embarrassment about the medical examination as an actual ${ }^{45}$ or anticipated ${ }^{464}$ barrier to help-seeking in the patient interval in India ${ }^{46}$ and in African countries ${ }^{45} 47$ (table 3).

Cancer knowledge. Lower cancer symptom knowledge was associated with longer anticipated patient intervals in three hypothetical studies with various cancers in Jordan ${ }^{48}$ and lung cancer in Nigeria, ${ }^{50}$ while one hypothetical study found no association between ovarian cancer symptom knowledge and anticipated time to helpseeking in Jordan. ${ }^{51}$ In hypothetical studies, good lung cancer symptom knowledge was associated with higher educational attainment and higher income in Nigeria, ${ }^{50}$ while good ovarian cancer symptom knowledge was associated with higher income, but not educational attainment in Jordan. ${ }^{51}$ Living in an urban area in India was associated with good breast cancer symptom knowledge in one hypothetical study. ${ }^{30}$

Misattribution of symptoms ${ }^{12} 323440444552$ was associated with a longer patient interval in seven observed studies of patients with breast, ${ }^{3844} 4552$ colorectal, ${ }^{40}$ cervical $^{39}$ and oral $^{53}$ cancers (table 3). Absence of pain was reported as a barrier to help-seeking in the patient interval in four observed studies of patients with breast cancer ${ }^{45} 5455$ or Kaposi sarcoma ${ }^{28}$ (table 3).

Emotional barriers to help-seeking. Fear of cancer was a barrier to help-seeking in the patient interval in five observed studies of patients with breast ${ }^{32} 354244$ and oral cancers $^{53}$ in African, Asian and Caribbean countries (table 3). Fear of breast cancer surgery was not associated with longer patient intervals in one observed study conducted in Uganda. ${ }^{34}$ Concerns about escalation of their cancer and a negative impact on relationships led to refusal of treatment in two observed studies of patients with breast cancer conducted in African countries. ${ }^{3856}$

Access barriers. In four observed studies, long travel times to hospital were reported in African countries ${ }^{35} 3657$ and in Indonesia ${ }^{31}$ (table 3). In two hypothetical studies conducted in Jordan, participants anticipated difficulty in arranging transport as a possible barrier in the patient interval $^{489}$ (table 3$)$. 
Table 3 Summary of narrative synthesis for quantitative studies

\begin{tabular}{lll} 
Measure & $\begin{array}{l}\% \text { of participants endorsed }- \\
\text { observed studies }\end{array}$ & $\begin{array}{l}\% \text { of participants endorsed }- \\
\text { hypothetical studies }\end{array}$ \\
\hline
\end{tabular}

\section{Patient interval}

Cancer knowledge

\begin{tabular}{|c|c|c|}
\hline Initially unaware their symptoms could indicate cancer & $\begin{array}{l}23 \%^{32} ; 40 \%^{12} ; 47 \%{ }^{44} ; 59 \%{ }^{40} \\
66 \%^{45} ; 69 \%^{34} ; 78 \%{ }^{52}\end{array}$ & - \\
\hline Absence of pain & $4 \%^{55} ; 17 \%^{54} ; 42 \%^{45} ; 48 \%{ }^{28}$ & - \\
\hline \multicolumn{3}{|l|}{ Emotional barriers to help-seeking } \\
\hline Fear of cancer & $\begin{array}{l}6 \%^{32} ; 6 \%^{35} ; 11 \%^{44} ; 38 \%^{53} \\
71 \%^{42}\end{array}$ & - \\
\hline
\end{tabular}

\begin{tabular}{|c|c|c|}
\hline \multicolumn{3}{|l|}{ Access barriers } \\
\hline Anticipated difficulty in arranging transport & - & $29 \%^{49} ; 49 \%^{48}$ \\
\hline \multicolumn{3}{|l|}{ Financial barriers } \\
\hline Anticipated medical costs & - & $42 \%{ }^{48} ; 68 \%{ }^{47} ; 83 \%{ }^{49}$ \\
\hline Financial barriers & $\begin{array}{l}2 \%^{41} ; 3 \%{ }^{58} ; 6 \%{ }^{39} ; 7 \%^{45} \\
14 \%{ }^{35} ; 17 \%{ }^{43} ; 21 \%^{44} ; 24 \%{ }^{57} \\
25 \%^{54} ; 25 \%^{12} ; 32 \%^{28} ; 35 \%^{33} \\
75 \%{ }^{36} ; 75 \%{ }^{53} ; 76 \%{ }^{42}\end{array}$ & - \\
\hline \multicolumn{3}{|l|}{ Cancer beliefs } \\
\hline Aware of the benefits of early breast cancer diagnosis & $77 \%{ }^{53}$ & $41 \%{ }^{59} ; 58 \%{ }^{37} ; 83 \%{ }^{29}$ \\
\hline Belief that breast cancer is incurable & $63 \%{ }^{60}$ & $53 \%^{37}$ \\
\hline Belief that cancer is curable & $93 \%^{57}$ & - \\
\hline Belief that cancer is caused by evil spirits & $60 \%{ }^{60}$ & $40 \%{ }^{59}$ \\
\hline Belief that rituals and worshipping could cure cancer & $35 \%{ }^{60}$ & \\
\hline \multicolumn{3}{|l|}{ Gender roles } \\
\hline Competing priorities (eg, housework or childcare) & $\begin{array}{l}7 \%^{45} ; 7 \%^{32} ; 7 \%^{35} ; 12 \%^{41} \\
77 \%^{42}\end{array}$ & - \\
\hline Embarrassment about the examination & $6 \% 45$ & $7 \%{ }^{47} ; 15 \%{ }^{46}$ \\
\hline \multicolumn{3}{|l|}{ Pretreatment interval } \\
\hline Fear of escalation & $25 \%^{38}$ & - \\
\hline $\begin{array}{l}\text { Fear that treatment would have a negative impact on their } \\
\text { relationship }\end{array}$ & $21 \%{ }^{38}$ & - \\
\hline Refusal of treatment due to emotional barriers & $31 \%{ }^{56}$ & - \\
\hline \multicolumn{3}{|l|}{ Access barriers } \\
\hline $2+$ hours' travel time to the hospital & $19 \%{ }^{35} ; 50 \%^{57} ; 69 \%^{31}$ & - \\
\hline $4+$ hours' travel time to the hospital & $43 \%^{36}$ & - \\
\hline \multicolumn{3}{|l|}{ Financial barriers } \\
\hline Financial barriers & $47 \%{ }^{56} ; 75 \%{ }^{36}$ & - \\
\hline Reliance on family and friends to fund treatment costs & $61 \%^{57} ; 75 \%{ }^{36}$ & - \\
\hline
\end{tabular}

The symbol (-) refers to not applicable or data not available.

Financial barriers. In three hypothetical studies ${ }^{47-49}$ and 15 observed studies of patients with breast ${ }^{33} 3541-4554$ and non-breast $^{12} 283639535758$ cancer conducted in African, Asian and Caribbean countries, participants cited financial barriers as major contributors to longer patient intervals or not seeking medical help for symptoms ${ }^{33} 58$ (table 3). In two observed studies conducted in African countries, patients with breast cancer refused ${ }^{56}$ or postponed treatment ${ }^{36}$ due to financial issues (table 3 ). Participants in observed studies conducted in African countries reported having to rely on gift/loans from friends and family during the pretreatment interval to fund treatment for various cancers ${ }^{36}$ (table 3 ).

Cancer beliefs. Three hypothetical studies conducted in India ${ }^{29}$ and in African countries ${ }^{37} 59$ reported awareness of the benefits of early breast cancer diagnosis. One hypothetical breast cancer study conducted in Kenya ${ }^{37}$ and one observed study conducted in India with various cancers ${ }^{60}$ reported beliefs that cancer was incurable (table 3). Negative breast cancer beliefs were more prevalent in women 
living in urban areas in Morocco in one observed study ${ }^{45}$; conversely, one hypothetical study reported higher negative beliefs about breast cancer among women living in rural areas in India. ${ }^{30}$ Participants in an observed study in India with various cancers believed that cancer was caused by evil spirits and could be cured by rituals and worshipping. ${ }^{60}$ In one hypothetical study conducted in Nigeria, women believed that breast cancer was caused by evil spirits. ${ }^{59}$ In an observed study of multiple cancers conducted in India, over half of the sample thought that cancer was contagious or were unsure, with those from lower socioeconomic groups more likely to believe that cancer was contagious. ${ }^{60}$

Social influences. In two observed studies of patients with ora ${ }^{53}$ and breast ${ }^{61}$ cancers conducted in Pakistan, encouragement to seek medical help from their social network promoted help-seeking in the patient interval ${ }^{5361}$ and attendance for diagnostic appointments in the diagnostic interval. ${ }^{61}$ However, one observed study conducted in Pakistan found that patients with breast cancer who disclosed symptoms to their social network experienced longer patient intervals. ${ }^{32}$ One observed study conducted in Uganda found that patients with breast cancer with no social support experienced longer patient intervals. ${ }^{34}$

\section{Qualitative studies: meta-ethnography}

Narrative summary data (third order) are presented below. Supporting illustrative participant quotes (firstorder data) are presented in table 4 .

TCAM. Most studies reported that the use of TCAM lengthened the patient, diagnostic and pretreatment intervals. In observed studies in Indonesia and in African countries, TCAM was typically sought prior to modern medicine in the patient interval, ${ }^{62-67}$ after diagnosis in the pretreatment interval ${ }^{6869}$ or both ${ }^{70}$ highlighting that help-seeking and accessing healthcare is a non-linear process.

In hypothetical and observed studies mostly conducted in African countries, it was common to believe that breast $^{116466676971-74}$ and prostate ${ }^{75}$ symptoms were caused by evil spirits, a spell, or witchcraft or a benign cause (eg, 'a boil'). ${ }^{6672} 73$ Beliefs about causality generally prompted participants to visit TCAM healers in the patient interval in observed studies of patients with breast cancer in African countries. ${ }^{626469727476}$ Due to causal beliefs, TCAM was seen as a logical option to resolve symptoms and treat the perceived underlying cause in the patient interval, and was strongly influenced by cultural norms around TCAM use in Indonesia ${ }^{6877}$ and in African countries. ${ }^{6466} 697578$ In hypothetical ${ }^{7379}$ and observed ${ }^{636566}$ studies conducted in African countries and Indonesia, participants reported beliefs that traditional medicine could cure breast, ${ }^{636673}$ nasopharyngea ${ }^{65}$ and cervical ${ }^{79}$ cancers; whereas Egyptian participants in a hypothetical breast cancer study tended to believe that traditional medicine could only cure non-cancer conditions such as coughs and colds. ${ }^{80}$

Help-seeking from TCAM practitioners after diagnosis substantially lengthened the pretreatment interval. In
African countries and in Indonesia, TCAM was commonly sought after diagnosis in patients with breast ${ }^{6264666978}$ and non-breast ${ }^{6568}$ cancer. In these studies, use of TCAM in the pretreatment interval was usually encouraged by friends / family due to perceived affordability, ${ }^{376265686978}$ easier access ${ }^{3765}$ and more trusted care ${ }^{64-666879}$ when compared with modern medicine. In observed studies of patients with breast cancer conducted in African countries, TCAM was sought in the pretreatment interval to avoid mastectomy, thereby preserving breasts to avoid social exclusion. ${ }^{63} 666977$ In African patients with breast cancer, biomedical cancer treatment was sought in the pretreatment interval when symptoms did not resolve or worsened, typically at an advanced cancer stage. ${ }^{63646678}$

Gender effects. In observed studies of patients with breast $^{62637481}$ and oral ${ }^{82}$ cancers, and hypothetical breast cancer studies ${ }^{3773}$ conducted in African and Asian countries, it was common for women to require permission from the family, usually their husband, prior to helpseeking in the patient interval ${ }^{37626373748182}$ and for husbands to make the final decision regarding treatment in the pretreatment interval. ${ }^{74}$ In observed breast cancer studies conducted in African and Asian countries, husbands were a key influence on either prompting helpseeking or refusing permission to seek medical help in the patient interval or treatment in the pretreatment interval. ${ }^{62} 63697481$ However, sometimes the husband's decision was over-ridden by the extended family. ${ }^{63} 81$ Breast examination by a male doctor was reported to be a key barrier in the patient and diagnostic intervals for Indian, ${ }^{67}$ Egyptian $^{80}{ }^{83}$ and Bangladeshi ${ }^{81}$ women due to cultural beliefs about modesty. ${ }^{670} 8183$

As primary caregivers, women in observed and hypothetical studies conducted in Indonesia and African countries reported prioritising family and work commitments over their personal health as barriers to help-seeking for breast ${ }^{646667707378}$ and non-breast ${ }^{136879}$ cancer symptoms in the patient interval. Medical help was sought in exceptional circumstances, typically if they were in pain and could not carry out domestic or childcare responsibilities. ${ }^{70}{ }^{80}$ Limited financial resource meant that healthcare costs for women were often lower in priority, and when women in breast cancer studies eventually sought medical help/treatment in all intervals, some described feeling guilty about using limited financial resources towards medical costs. ${ }^{72} 7377$

Cancer knowledge. Knowledge of breast ${ }^{63} 6473768083$ and non-breast ${ }^{65}$ cancer was generally obtained from social networks, although some participants in African ${ }^{13} 64$ 71-73 and Egyptian ${ }^{80}$ breast cancer studies described the influence of cancer awareness campaigns. The point of diagnosis for some African patients with breast cancer ${ }^{636466}$ and Indonesian patients with nasopharyngeal ${ }^{65}$ cancer in observed studies was the first time they had heard of cancer.

In observed and hypothetical studies conducted in Asian and African countries, breast, ${ }^{80} 81$ cervical, ${ }^{13}$ prostate $^{75}$ and oral ${ }^{82}$ cancer symptom knowledge was poor 
Table 4 Supporting quotes (first-order data) from meta-ethnography

Theme

Subtheme

Example quotations

Patient interval

Knowledge of cancer

Symptom detection

'After work, I came back home and while eating my second spoon, suddenly, as we say, an ant bit me in my breast. I stood up and removed my clothes. And automatically I saw a lump which I had never noticed before.' (Breast cancer, observed, Mali ${ }^{11}$ )

Self-examination behaviour/ source of symptom knowledge

'Based on the education for frequent checks of the breast for cancer lumps, I developed the routine checks daily. It was during one of those checks for lumps that I identified the lump in my breast the very first month I had my menopause.' (Breast cancer, observed, Ghana ${ }^{71}$ )

Symptom knowledge restricted ' 'Lump-the only one known - there could be other signs but lump is all that is known.' (Breast cancer, hypothetical to lumps and observed, Kenya ${ }^{76}$ )

Pain as a motivator for helpseeking

'I came with my sister. She told me she had a lump on her breast about twoyears back. We were not worried that much because it was painless. But, starting last year, the lump become painful and we took her to [a clinic].' (Breast cancer, observed, Ethiopia ${ }^{84}$ )

Change in symptoms as a motivator for help-seeking 'About 2 years back, I found a small hard lump over my left breast, but since it was small and I had no pain, I was not that much concerned about it. But it kept getting bigger and bigger...' (Breast cancer, observed, Ethiopia ${ }^{84}$ )

Lack of knowledge of cancer as a disease

'I had absolutely no idea what breast cancer was or any knowledge about the disease and symptoms before my diagnoses. I was totally ignorant about what was going on in my breast. Therefore, I did not take any action earlier.' (Breast cancer, observed, Ghana ${ }^{64}$ )

Low knowledge of the aetiology 'I have never seen someone with this disease before in my home. How would I have known that it was a bad of disease

Knowledge of cancer obtained from social networks disease, cancer? I just thought it would go away.' (Breast cancer, observed, Ghana ${ }^{63}$ )

Educational cancer awareness programmes

'This disease is very dangerous; I have seen my relatives and my neighbor who had breast cancer. They did not recover and finally died.' (Breast cancer, observed, Indonesia ${ }^{77}$ )

'They come and tell us in the church, before I know that there is something like that [breast cancer] to check the breasts.' (Breast cancer, observed, Ghana ${ }^{72}$ )

Reliance on traditional,

\section{complementary and alternative}

medicine (TCAM)

Use of TCAM due to beliefs about causality

'I had a prophecy at church some months ago that a family witch (evil spirit) has bought breast cancer for me; just to destroy and kill me. I got delivered spiritually though. Hence, when it manifested physically as a lump in the breast, I took the spiritual route; I went for prayers. I deemed it as not a hospital disease; I ignored hospitals for more than a year.' (Breast cancer, observed, Ghana ${ }^{64}$ )

Cease TCAM and seek medical 'They [men] go first to the traditional healer because he or she is versed with the traditional treatment. If it doesn't help when TCAM was considered work, then they go to the hospital.' (Prostate cancer, hypothetical, Cameroon ${ }^{75}$ ) ineffective

\section{Stigma}

Fear of disownment/divorce if diagnosed with cancer

'Maybe if a girl is known to have breast cancer, one may be divorced if she is married. If a girl gets cancer and one of her breasts is removed obviously that one will be rejected. One time...a woman had cancer. The husband's family did not want her...They disowned her.' (Breast cancer, hypothetical, Kenya ${ }^{37}$ )

Cancer fatalism 'For us cancer means death has arrived.' (Prostate cancer, hypothetical, Cameroon ${ }^{75}$ )

Cancer fatalism 'When I hear the word cancer, I see death, I see a growth that leads to death.' (Breast cancer, hypothetical and observed, Kenya ${ }^{76}$ )

Belief that their cancer was $\quad$ 'He said my husband fought with somebody and that, that person [cast a spell]... so the spell was meant for my caused by a spell husband but it did not get him so it attacked me.' (Breast cancer, observed, Ghana ${ }^{72}$ )

Belief that their cancer was a spiritual attack

'My cancer is a spiritual attack, it is caused by witches and wizards, I [knew] it would happen. I was told that cancer arrow would be fashioned.' (Breast cancer, observed, Nigeria ${ }^{74}$ )

\section{Social influences}

Lay symptom disclosure facilitated 'After a year, I went to [Eastern Ethiopia] where my biggest child lives. I told him that I had a lump on my breast. I symptom interpretation and think he heard about breast cancer. He immediately took me to nearby clinic.' (Breast cancer, observed, Ethiopia ${ }^{84}$

promoted medical help-seeking

Lay symptom disclosure facilitated 'I showed it to many people, some said maybe you are approaching menopause, others said that it is nothing. misattribution After I saw two lumps appearing, without any pain but which were growing, I showed it to a pharmacist who called [name]. He told me it is a furuncle but taking antibiotics will prevent it from growing. I talked to my husband who said that I have nothing and that I talk too much.' (Breast cancer, observed, Mali ${ }^{11}$ )

Seek symptom advice from 'I told my pastor and then he recommended Dr. X.' (Breast cancer, observed, Ghana ${ }^{72}$ )

religious leader

$\begin{array}{ll}\text { Husband prompted help-seeking } & \text { 'I first told my husband. My husband told me to go to the hospital immediately.' (Cervical cancer, observed, } \\ & \text { Uganda }{ }^{13} \text { ) } \\ \begin{array}{ll}\text { Husband encouraged help- } & \text { 'I told my husband. He told me that he has no money and that I should ask God for help and see a traditional healer. } \\ \text { seeking from TCAM } & \text { His younger brother also said someone has put a spell on me.' (Breast cancer, observed, Mali1 }{ }^{11} \text { ) }\end{array}\end{array}$


Table 4 Continued

Theme

Subtheme

Example quotations

Gender roles

Women prioritise family and work commitments over their personal health

'Women have no time for themselves. You take care of the children; you take care of the husbands, the shamba [vegetable garden], and everything, even the [extended] family... In fact, there are few of us who take care of ourselves such as going for a walk or going for aerobics. If you take a holiday, people will look at you. You are seen as somebody who is not okay. It is not in our culture.' (Breast cancer, hypothetical, Kenya ${ }^{73}$ )

Women typically suffer in silence 'A woman doesn't know how to be sickly or pity herself...If the husband falls sick, he exaggerates his illness, but the wife bears her sickness in silence and hides it.' (Breast cancer hypothetical, Kenya ${ }^{73}$ )

Male health prioritised 'A woman can bear it if it is a serious disease but a man says "No I cannot, I must see a doctor quickly".' (Breast cancer, hypothetical, Egypt ${ }^{80}$ )

Women's health relegated to second place

'Our society is male dominant, and here women are often neglected. It is the same for government and everyone else. This is one of the reasons why the awareness of this kind of disease [breast cancer] is almost non-existent.' (Breast cancer, observed, Bangladesh ${ }^{81}$ )

\section{Diagnostic interval}

Difficulty navigating the healthcare 'I went around looking for doctors, as I didn't know anything about this subject. Nor did I know what doctor to go to, system should he be a surgeon or a medical doctor? All these things I knew very late.' (Breast cancer, observed, Egypt ${ }^{83}$ )

Power imbalance between doctor 'We listen to what the doctor says because the doctor knows, he was trained in many things. You don't know and patient anything. So if he tells you to do something, you have to do it.' (Breast cancer, observed, Malawi ${ }^{70}$ )

Embarrassment of examination 'It is embarrassing to have a breast examination by a male doctor.' (Breast cancer, hypothetical, Egypt ${ }^{80}$ )

from a male doctor

System barriers

'It took three years for me to know that it was cancer because they took it [sample] to Blantyre. In the first year, it got lost. They took another sample. It got lost again. During the third time, that was when they diagnosed cancer of the breast.' (Breast cancer, observed, Malawi ${ }^{70}$ )

\section{Pretreatment interval \\ Reliance on TCAM}

Belief that TCAM can cure cancer 'There is a strongly held belief among men in Bamenda that diseases like prostate cancer need to be treated as a spiritual illness and traditional medicine is better suited for such.' (Prostate cancer, hypothetical, Cameroon ${ }^{75}$ )

Use of TCAM due to fear of

'I was really afraid of surgery, it was not wrong to try another treatment such as herbal medicine and another surgery method of traditional treatment which were more comfortable for me.' (Breast cancer, observed, Indonesia ${ }^{77}$ )

Use of TCAM as a cure for cancer 'I don't know the names of all the herbs; knowledge is inherited from previous generations, my grandparents [...] I'm and for perceived affordability using alternative treatment because I just want to be cured. Besides that, it is more affordable.' (Nasopharyngeal cancer, observed, Indonesia ${ }^{65}$ )

\section{Stigma}

Health professionals inform families of diagnosis rather than the patient

Fear of cancer stems from social networks

\section{Beliefs about cancer being} contagious

The need to refocus the mind to cope with a diagnosis of cancer

\section{Religious beliefs to cure cancer}

The need to maintain a positive attitude to cure cancer

\section{Fear of modern biomedical treatment}

Belief that modern medicine was ineffective and invasive

'External' cancers perceived as
more treatable than 'internal'
cancers

Preference to die from cancer than undergo mastectomy

Divorce after mastectomy
'It was my sister and her husband who were informed and they did not want to tell me because I tend to overreact.' (Breast cancer, observed, Mali ${ }^{11}$ )

'I felt it was the end of the world, because I had not seen anyone who recovered from it.' (Breast cancer, observed, Uganda $^{78}$ )

'People say it is contagious, and some say not. They think that I should not make food for them. They are frightened of me. They fear me. I am frightened my children will get it. I feel as if I am a germ.' (Breast cancer, observed, Egypt $^{83}$ )

'Everything is from the mind; this is what I always say. If you tune your mind, you will be okay.' (Breast cancer, observed, Ghana ${ }^{71}$ )

'This cancer is my destiny; I just have to be patient, accept my condition and try to seek a treatment, but only God can heal.' (Breast cancer, observed, Indonesia ${ }^{77}$ )

'This cancer is painful, but I'm going to fight back. It is going to hurt me, but I am also going to fight back. I am not going to allow it to get over me. I decided to remain positive despite what has happened.' (Breast cancer, observed, Uganda $^{78}$ )

'I was told that cancer medicine kills everything-good and bad inside you. I decided to keep living and not kill myself with those dangerous medicines.' (Breast cancer, observed, Ghana ${ }^{63}$ )

'The simplest form of cancer as far as I know is breast cancer. Someone who has colon cancer has lots of operations. When I had the operation, I felt that the operation recovered the person, and it was over in a certain period of time. Cancer of the lung very bad, cancer of the colon bad.' (Breast cancer, observed, Egypt ${ }^{83}$ )

'A woman's glory is her breast, so what is your use if one of your breasts is not there? I will rather die with my two breasts than live with one.' (Breast cancer, observed, Ghana ${ }^{72}$ ) 'My husband even wanted a divorce because he said I had been maimed.' (Breast cancer, observed, Ghana ${ }^{72}$ ) 
Table 4 Continued

Theme

Subtheme

Example quotations

Removal of breasts considered to 'Some think that if you have no breast then your husband would not have something to hold; there are many places diminish a woman's sexual identity the man can play with; so one can still have a fulfilling relationship with a man.' (Breast cancer, observed, Ghana ${ }^{71}$ )

Modern biomedical medicine

Suspicion about modern medicine 'They say medicines given from hospital here [to the community] could be family planning pills given secretly, and many of them are not ready to do family planning. Others even say that [community outreach] is an organization for devil worshippers.' (Breast cancer, hypothetical, Kenya ${ }^{37}$ )

High financial cost of modern medicine

'If you don't have the financial power, neither you nor your husband, they don't care for you, even if you cry; but if they know you have money, they give you attention. That's why I am using traditional medicine.' (Breast cancer, observed, Mali ${ }^{11}$ )

Reluctance to use government

'I would like to pay no matter what, my son told me not to use BPJS they would treat us like less important.' assistance for medical bills due to (Nasopharyngeal cancer, observed, Indonesia ${ }^{65}$ )

fear of mistreatment

\begin{tabular}{|c|c|}
\hline Access problems & $\begin{array}{l}\text { 'I was worried about transport [...] If it was near, I could have been coming sooner.' (Breast cancer, observed, } \\
\text { Malawi }{ }^{7} \text { ) }\end{array}$ \\
\hline \multicolumn{2}{|l|}{ Economic hardship } \\
\hline High transportation costs & $\begin{array}{l}\text { 'We rely on farming in order to find money for transport...[we were] waiting until we sell tobacco to find money to } \\
\text { use for transport to go.' (Breast cancer, observed, Malawi }{ }^{70} \text { ) }\end{array}$ \\
\hline $\begin{array}{l}\text { Did not accept treatment due to } \\
\text { cost }\end{array}$ & $\begin{array}{l}\text { 'Immediately I went to the lab and came here, they immediately scheduled me for surgery. I didn't have money so I } \\
\text { went home and never came back because I didn't have money... I run away because of the money.' (Breast cancer, } \\
\text { observed, Ghana }{ }^{72} \text { ) }\end{array}$ \\
\hline $\begin{array}{l}\text { Prioritising educational bills over } \\
\text { medical bills }\end{array}$ & $\begin{array}{l}\text { 'At the time I discovered this lump in my breast, my daughter had just been accepted into [university] to study } \\
\text { nursing... I didn't come [follow up with treatment] because I wouldn't have been able to work to provide [financially] } \\
\text { for my child and I would have destroyed her life... so I wanted to her to go because I knew that even if I had passed } \\
\text { away, she would have entered the University.' (Breast cancer, observed, Ghana }{ }^{72} \text { ) }\end{array}$ \\
\hline \multicolumn{2}{|l|}{ Social influences } \\
\hline $\begin{array}{l}\text { Husband refused permission to } \\
\text { seek medical; family over-rode } \\
\text { decision }\end{array}$ & $\begin{array}{l}\text { 'My husband was against mastectomy, but my mother and uncle prevailed upon me to have it. I obeyed my mother } \\
\text { and uncle and had the mastectomy even though I thought just removing the lump would be okay since the breast } \\
\text { looked normal.' (Breast cancer, observed, Ghana }{ }^{63} \text { ) }\end{array}$ \\
\hline $\begin{array}{l}\text { Husband refused permission for } \\
\text { mastectomy }\end{array}$ & $\begin{array}{l}\text { 'A day to the operation, my husband decided not to allow the operation to come on. I was subsequently discharged } \\
\text { even though the doctor wasn't happy about it. I was taken to a(n) herbalist. In fact, I went through a lot.' (Breast } \\
\text { cancer, observed, Ghana }{ }^{63} \text { ) }\end{array}$ \\
\hline Accepting God's will & $\begin{array}{l}\text { 'According to the bible in Jeremiah } 30: 17 \text {; the word of God says that "I shall be whole again", I believe that they will } \\
\text { not cut it and the lump will go.' (Breast cancer, observed, Nigeria }{ }^{74} \text { ) }\end{array}$ \\
\hline
\end{tabular}

and mainly restricted to lumps as a cancer symptom. ${ }^{647376}$ In observed studies of patients with breast cancer, misattribution of symptoms contributed to longer patient intervals. 116364667072747677818284 Lack of pain was a key barrier to help-seeking in the patient interval in observed breast cancer studies conducted in African countries due to misattribution. ${ }^{62-646670727484}$ Painless symptoms and/or symptoms that did not hinder daily functioning lengthened the patient interval in observed studies of African patients with breast cancer 636466747884 and Indonesian patients with nasopharyngeal ${ }^{65}$ cancer. Symptoms that persisted, changed or became painful motivated help-seeking in the patient interval in observed studies of patients with breast ${ }^{62-6470788384}$ and cervical $^{13}$ cancers.

Stigma. In hypothetical and observed studies conducted in Asian and African countries, cancer was a source of shame and stigma ${ }^{72} 75-7782$ that influenced help-seeking across all intervals due to fear of social rejection and treatment, and presumed death after diagnosis. 3762758182 In Indonesia and in African countries, cultural norms around cancer stigma and secrecy after breast ${ }^{63} 72747677$ and prostate ${ }^{75}$ cancer diagnosis meant that there was a lack of exposure to cancer, and negative illness synonyms such as 'the bad disease ${ }^{\text {, }} 647680$ were used. Cancer taboo was reinforced in hospital settings in African countries where health professionals referred to cancer as 'that disease' or 'the sickness', 72 and commonly withheld details of the diagnosis from the patient. ${ }^{74}$

In observed and hypothetical studies conducted in Asian and African countries, breast ${ }^{1162646667697273777881}$ and oral ${ }^{82}$ cancer stigma stemmed from beliefs about the causes of cancer in general, where cancer was mainly viewed as a form of punishment, out of one's control

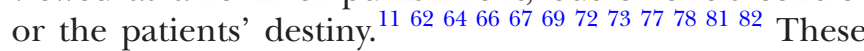
beliefs lead to fear of disownment or mistreatment from family or the community in Asian and African countries. ${ }^{37677276-788183}$ Participants in observed breast cancer studies reported that seeking social support after diagnosis in the pretreatment interval was potentially risky due to stigma associated with cancer. ${ }^{64} 74$ In observed studies, strong religious beliefs facilitated acceptance of the consequences of their cancer in Indonesian patients with nasopharyngeal cancer ${ }^{65}$ and Ghanaian patients with breast cancer ${ }^{63}$ leading to refusal of cancer treatment, accepting God's will or entrusting God to cure the cancer without the need for biomedical treatment. ${ }^{63-65747782}$ 
Financial barriers. In hypothetical and observed studies, high medical and transportation costs were a major barrier in Asian and African studies across all intervals, ${ }^{11} 13626365-78808183$ particularly for patients living in rural areas. Many participants did not have healthcare insurance, or insurance coverage was limited to certain treatments. ${ }^{65} 72757783$ The pretreatment interval in Asian and African studies was lengthened while patients with breast ${ }^{11} 6270778183$ and non-breast ${ }^{1365} 68$ cancer in observed studies obtained the financial means to cover medical costs and/or transport, often using more affordable TCAMs. Patients in observed breast and non-breast cancer studies conducted in Indonesia and African countries $^{116270-7274}$ relied on relatives, the community and the church for financial support for medical bills and transport costs which shortened the pretreatment interval.

Social influences. Social networks-family, friends, the local community, elders, the church-were found to play a pivotal role in help-seeking at all intervals. In observed studies conducted in African and Asian countries, typically spouses, close relatives or church leaders were consulted on discovery of a breast ${ }^{636470-727884}$ or non-breast ${ }^{13} 6582$ symptom. Symptom disclosure could lengthen or shorten the patient interval in observed studies of patients with breast and non-breast cancer conducted in Asian and African countries depending on whether symptoms were attributed to cancer by friends and family ${ }^{11} 1363-656970727478$ 82-84 and whether patients were encouraged to seek help from TCAM ${ }^{1162-64697074}$ or modern medicine. ${ }^{11136465707274788284}$

Beliefs about cancer. Most studies assessing fearful and fatalistic cancer beliefs found that these lengthened all intervals. In observed and hypothetical studies conducted in Asian and African countries, breast, ${ }^{3762-6466677374767780}$ nasopharyngeal, ${ }^{65}$ oral $^{82}$ and prostate $^{75}$ cancers were conceptualised as dangerous, painful and deadly. Negative beliefs were usually based on experiences of people within patients' social network with a cancer diagnosis. ${ }^{62-64} 66$ 74-78 83 There were few accounts of positive survival stories. ${ }^{74}$

For women in observed breast cancer studies conducted in African countries, the possibility of disfigurement lengthened the pretreatment interval or led to treatment refusal. ${ }^{636972} 7478$ In hypothetical and observed studies conducted in Indonesia ${ }^{77}$ and in African countries, ${ }^{376369717278}$ the removal of a woman's breasts through mastectomy was considered to diminish her sexual identity, self-worth, personal relationships and value in society. In hypothetical and observed breast cancer studies, women recounted examples of cancer diagnoses that resulted in divorce or social rejection. ${ }^{377274767881}$

Modern medicine. One hypothetical breast cancer study conducted in Egypt reported positive views towards modern cancer treatment, ${ }^{80}$ although few women in hypothetical and observed breast cancer studies reported knowledge about the benefits of early diagnosis for breast cancer. ${ }^{6272737680}$ In most observed and hypothetical studies conducted across African and Asian contexts, modern biomedical treatment for breast ${ }^{6364666770-727781}$ and nonbreast $^{65} 7579$ cancer was generally perceived as expensive, invasive and ineffective, with harmful side effects that destroy the body and/or lead to disfigurement and shame. In some hypothetical and observed studies conducted in African countries, breast cancer surgery was believed to escalate cancer progression. ${ }^{62} 727377$

Suspicion and mistrust of biomedical care in Asian and African countries lengthened the patient and pretreatment intervals in observed breast cancer studies, and prompted visits to TCAM practitioners. ${ }^{1166} 6769707683$ In hypothetical and observed studies conducted in African and Asian countries there was a perceived imbalance of power between doctors and patients, with reports of health professionals dominating discussions about treatment and lacking empathy. ${ }^{65-67} 69707376777983$ Patients with breast ${ }^{67} 707677$ and nasopharyngeal ${ }^{65}$ cancers in observed studies were reluctant to question their diagnosis or ask questions in Asian and African countries. This power imbalance was most prominent in uninsured, lower income, less educated and rural patients, where some studies reported instances of mistreatment or suboptimal treatment. ${ }^{1165767779}$ In observed studies of patients with breast ${ }^{117677}$ and nasopharyngeal ${ }^{65}$ cancers, some low-income uninsured patients who were eligible for government assistance to cover healthcare costs sometimes described refusing the financial support due to fear of differential treatment by medically trained health professionals.

\section{DISCUSSION}

This was the first comprehensive review of psychosocial barriers to medical help-seeking behaviour for cancer symptoms and access to healthcare in LMICs. Use of TCAM was a key barrier to prompt medical help-seeking in LMICs. Consulting TCAM was influenced by causal beliefs about symptoms, familial pressure to visit a traditional healer, ease of access, affordability and a preference to avoid biomedical treatment. Biomedical treatment was perceived as invasive, disfiguring, ineffective and expensive, and in some contexts medically trained doctors were perceived as untrustworthy and corrupt. Fear, shame and stigma associated with cancer were a barrier to help-seeking that prompted refusal of treatment due to fear of social rejection. Women were seen as having particular high levels of challenges and barriers to prompt cancer help-seeking, such as needing permission from the husband or family to contact the medical system, their health being seen as lower value and femalespecific stigma around breast cancer. The cost of travel and healthcare appointments/treatment was a key barrier across all intervals.

Consistent with previous narrative reviews and one meta-analysis conducted in HIC and/or LMIC contexts, low symptom knowledge, ${ }^{14} 1585$ misattribution of symptoms, ${ }^{161985}$ negative beliefs about cancer ${ }^{141819}$ and fear of treatment ${ }^{1786}$ were associated with longer patient intervals, 
suggesting these are universal barriers to cancer helpseeking. Findings from our meta-ethnography indicate that cancer is highly stigmatised in LMICs partly due to beliefs about causation and low knowledge of the disease, and impacts help-seeking across all intervals. One review of breast cancer studies in LMIC contexts found fair to moderate evidence that the use of TCAM healers lengthened the patient interval, ${ }^{17}$ while our updated review covering all cancers found strong evidence that use of TCAM was prevalent and a key influence on help-seeking across all intervals. No review in HIC has reported use of complementary medicines, suggesting that TCAM use may be particularly important in LMICs.

Due to the predominance of breast cancer studies and patient interval studies, we were unable to draw strong conclusions in relation to help-seeking in the diagnostic and pretreatment intervals, or for non-breast tumours and male help-seeking. Additionally, some findings were presented descriptively, meaning it was not possible to assess their influence on time to help-seeking. Heterogeneity among the quantitative studies precluded a formal meta-analysis ${ }^{87}$ due to inconsistencies in help-seeking thresholds (eg, definitions of 'delay' ranged from 2 weeks $^{50}$ to 6 months $^{84}$ ) and the use of a wide range of psychosocial measures, many of which were unvalidated, increasing the difficulty of integrating findings. There were additional inconsistencies in the reporting of statistical results, for example, not reporting non-significant findings and not providing full information needed to interpret statistical results. The quantitative study team met frequently to discuss each paper in detail and the data set as a whole to agree on which variables could be analysed using meta-analytic techniques. Due to consistency of reporting and the high number of studies that assessed TCAM use, TCAM use was the only variable that could be analysed using meta-analytic techniques. It is a limitation of our review that other non-TCAM variables could not be summarised using meta-analytic techniques for comparison. Due to small sample sizes, it was not possible to assess whether TCAM use varied as a function of region. There are methodological limitations associated with measuring observed and hypothetical helpseeking behaviour, with a possible intention-behaviour gap in hypothetical studies and recall bias in observed studies. We included both types of studies in our review to balance the limitations associated with each study design.

Future research on cancer help-seeking behaviour in LMICs should consider using validated measures ${ }^{78}$ with reporting of all statistical results (significant or not) and use of ORs, to allow for summarisation across studies. Freely available and validated measures include the Cancer Awareness Measure ${ }^{88}$ the Awareness and Beliefs about Cancer Measure, ${ }^{89}$ and the Cancer-Symptom Interval Measure. ${ }^{90}$ Pilot testing should be conducted with a sample of potential participants to ensure cultural relevance of translated or new survey items. A number of studies in our review included limited assessment of
TCAM, and further research is required to understand in depth the influences of TCAM on the patient interval.

Lack of symptom knowledge and negative beliefs about cancer appear to be universal barriers to cancer helpseeking behaviour, suggesting that elements of existing awareness campaigns (eg, Be Clear on Cancer; https:/ www.cancerresearchuk.org/health-professional/awareness-and-prevention/be-clear-on-cancer) could potentially be adapted for LMICs. Cultural and context-specific barriers reflecting TCAM use and gender influences on medical help-seeking are key barriers in LMICs that would need to be addressed sensitively and in collaboration with local communities.

\section{CONCLUSION}

With rapidly rising cancer incidence in LMICs, efforts to improve early cancer diagnosis and treatment through system-level interventions and individual behavioural interventions are critical to reduce cancer mortality. Interventions must address major barriers to medical help-seeking for symptoms and decisions to access healthcare for diagnosis and treatment in LMICs by raising cancer awareness, modifying negative beliefs and addressing cultural barriers such as TCAM use and barriers for women.

\section{Author affiliations}

${ }^{1}$ Division of Population Medicine, School of Medicine, Cardiff University, Cardiff, UK

${ }^{2}$ Wales Cancer Research Centre, Cardiff University, Cardiff, UK

${ }^{3}$ Department of Psychology and Human Development, Vanderbilt University,

Nashville, Tennessee, USA

${ }^{4}$ PRIME Centre Wales, Cardiff University, Cardiff, UK

${ }^{5}$ Department of Acute Medicine, Ysbyty Gwynedd, Betsi Cadwaladr University Health Board, Bangor, UK

${ }^{6}$ Center for Research, Information and Services in Psychology, Vietnam National University, Hanoi, Vietnam

${ }^{7}$ Danang Psychiatric Hospital, Da Nang, Vietnam

${ }^{8}$ Department of General Practice and Centre for Cancer Research, University of Melbourne, Melbourne, Victoria, Australia

Twitter Grace McCutchan @grace_mccutchan

Contributors GMC, KB and BW designed the review. GMC coordinated the review. GMC and TD designed and ran the literature search and screened records. GMC, $B W, H Q S, K B, A D, Y D$ and $H H$ extracted the data, assessed the quality of studies and conducted dual coding and data analysis. All authors contributed to interpretation of the data. GMC drafted the paper, and all authors critically revised the paper. All authors approved the final version.

Funding GMC and HQS were funded by the Health and Care Research Wales funded centres of the Wales Cancer Research Centre and the Primary and Emergency Care Research Centre Wales, respectively, to conduct this review. BW and AD were funded by the US NIH grant R21 TW011294.

Competing interests None declared.

Patient consent for publication Not required.

Provenance and peer review Not commissioned; externally peer reviewed.

Data availability statement Data are available upon request. All data will be made available upon reasonable request to the corresponding author.

Supplemental material This content has been supplied by the author(s). It has not been vetted by BMJ Publishing Group Limited (BMJ) and may not have been peer-reviewed. Any opinions or recommendations discussed are solely those of the author(s) and are not endorsed by BMJ. BMJ disclaims all liability and responsibility arising from any reliance placed on the content. Where the content includes any translated material, BMJ does not warrant the accuracy and reliability 
of the translations (including but not limited to local regulations, clinical guidelines, terminology, drug names and drug dosages), and is not responsible for any error and/or omissions arising from translation and adaptation or otherwise.

Open access This is an open access article distributed in accordance with the Creative Commons Attribution Non Commercial (CC BY-NC 4.0) license, which permits others to distribute, remix, adapt, build upon this work non-commercially, and license their derivative works on different terms, provided the original work is properly cited, appropriate credit is given, any changes made indicated, and the use is non-commercial. See: http://creativecommons.org/licenses/by-nc/4.0/.

\section{ORCID iDs}

Grace McCutchan http://orcid.org/0000-0002-8079-2540

Bahr Weiss http://orcid.org/0000-0001-6927-5297

\section{REFERENCES}

1 Jemal A, Torre L, Soerjomataram I. The cancer atlas, 2019. Available: https://canceratlas.cancer.org/wp-content/uploads/2019/10/ACS CA3_Book.pdf [Accessed 15 Sep 2020].

2 Fitzmaurice C, Allen C, et al. Global, regional, and National cancer incidence, mortality, years of life lost, years lived with disability, and Disability-Adjusted life-years for 32 cancer groups, 1990 to 2015: a systematic analysis for the global burden of disease study. JAMA Oncol 2017;3:524-48

3 Pesec M, Sherertz T. Global health from a cancer care perspective. Future Oncol 2015;11:2235-45.

4 Ismaila N, Salako O, Mutiu J, et al. Oncology guidelines usage in a low- and middle-income country. JGO 2018;4:1-6.

5 Whitaker K. Earlier diagnosis: the importance of cancer symptoms. Lancet Oncol 2020;21:6-8.

6 World Health Organisation. Guide to cancer early diagnosis, 2017. Available: www.who.int/cancer/publications/cancer_early_diagnosis/ en/ [Accessed 15 Sep 2020].

7 Weller D, Vedsted P, Rubin G, et al. The Aarhus statement: improving design and reporting of studies on early cancer diagnosis. $\mathrm{Br} J$ Cancer 2012;106:1262-7.

8 Coxon D, Campbell C, Walter FM, et al. The Aarhus statement on cancer diagnostic research: turning recommendations into new survey instruments. BMC Health Serv Res 2018;18:677.

9 Walter F, Webster A, Scott S, et al. The Andersen model of total patient delay: a systematic review of its application in cancer diagnosis. J Health Serv Res Policy 2012;17:110-8.

10 Scott SE, Walter FM, Webster A, et al. The model of pathways to treatment: conceptualization and integration with existing theory. $\mathrm{Br}$ $J$ Health Psychol 2013;18:45-65.

11 Grosse Frie K, Samoura H, Diop S, et al. Why do women with breast cancer get diagnosed and treated late in sub-Saharan Africa perspectives from women and patients in Bamako, Mali. Breast Care 2018;13:39-43.

12 Mwaka AD, Garimoi CO, Were EM, et al. Social, demographic and healthcare factors associated with stage at diagnosis of cervical cancer: cross-sectional study in a tertiary hospital in northern Uganda. BMJ Open 2016;6:9

13 Mwaka AD, Okello ES, Wabinga $\mathrm{H}$, et al. Symptomatic presentation with cervical cancer in Uganda: a qualitative study assessing the pathways to diagnosis in a low-income country. BMC Womens Health 2015;15:13.

14 Petrova D, Okan Y, Salamanca-Fernández E, et al. Psychological factors related to time to help-seeking for cancer symptoms: a metaanalysis across cancer sites. Health Psychol Rev 2020;14:245-68.

15 McCutchan GM, Wood F, Edwards A, et al. Influences of cancer symptom knowledge, beliefs and barriers on cancer symptom presentation in relation to socioeconomic deprivation: a systematic review. BMC Cancer 2015;15:1000.

16 Beaudoin P-L, Anchouche S, Gaffar R, et al. Barriers in access to care for patients with head and neck cancer in resource-limited settings. JAMA Otolaryngol Head Neck Surg 2020;146:291-7.

17 Sharma K, Costas A, Shulman LN, et al. A systematic review of barriers to breast cancer care in developing countries resulting in delayed patient presentation. J Oncol 2012;2012:1-8.

18 Akuoko CP, Armah E, Sarpong T, et al. Barriers to early presentation and diagnosis of breast cancer among African women living in subSaharan Africa. PLoS One 2017;12:e0171024.

19 Freitas AGQ, Weller M. Patient delays and system delays in breast cancer treatment in developed and developing countries. Ciênc. saúde coletiva 2015;20:3177-89.

20 Redaniel MT, Martin RM, Ridd MJ, et al. Diagnostic intervals and its association with breast, prostate, lung and colorectal cancer survival in England: historical cohort study using the clinical practice research Datalink. PLoS One 2015;10:e0126608.

21 Koo MM, Hamilton W, Walter FM, et al. Symptom signatures and diagnostic timeliness in cancer patients: a review of current evidence. Neoplasia 2018;20:165-74.

22 Noblit GW, Hare R. Meta-ethnography: synthesizing qualitative studies. California: Sage Publications, 1988.

23 Moher D, Liberati A, Tetzlaff J, et al. Preferred reporting items for systematic reviews and meta-analyses: the PRISMA statement. BMJ 2009;339:b2535.

24 Cooper C, Booth A, Varley-Campbell J, et al. Defining the process to literature searching in systematic reviews: a literature review of guidance and supporting studies. BMC Med Res Methodol 2018;18:85.

25 Hong QN, Pluye P, Bujold M, et al. Convergent and sequential synthesis designs: implications for conducting and reporting systematic reviews of qualitative and quantitative evidence. Syst Rev 2017;6:61.

26 Popay J, Roberts H, Sowden A. Guidance on the conduct of narrative synthesis in systematic reviews: a product from the ESRC methods programme. Lancaster University 2006.

27 France EF, Cunningham M, Ring N, et al. Improving reporting of meta-ethnography: the eMERGe reporting guidance. BMC Med Res Methodol 2019;19:25.

28 De Boer C, Niyonzima N, Orem J, et al. Prognosis and delay of diagnosis among Kaposi's sarcoma patients in Uganda: a crosssectional study. Infect Agent Cancer 2014;9:8

29 Gadgil A, Sauvaget C, Roy N, et al. Breast Cancer Awareness among Middle Class Urban Women--a Community-Based Study from Mumbai, India. Asian Pac J Cancer Prev 2015;16:6249-54.

30 Grunfeld EA, Kohli N. Beliefs about breast cancer and help-seeking intentions for the disease among women in India. Women Health 2010;50:327-41.

31 Iskandarsyah A, de Klerk C, Suardi DR, et al. Consulting a traditional healer and negative illness perceptions are associated with nonadherence to treatment in Indonesian women with breast cancer. Psychooncology 2014;23:1118-24.

32 Malik IA, Gopalan S. Use of CaM results in delay in seeking medical advice for breast cancer. Eur J Epidemiol 2003;18:817-22.

33 Ntirenganya F, Petroze RT, Kamara TB, et al. Prevalence of breast masses and barriers to care: results from a populationbased survey in Rwanda and Sierra Leone. J Surg Oncol 2014;110:903-6.

34 Odongo J, Makumbi T, Kalungi S, et al. Patient delay factors in women presenting with breast cancer in a low income country. BMC Res Notes 2015;8:467.

35 Pace LE, Mpunga T, Hategekimana V, et al. Delays in breast cancer presentation and diagnosis at two rural cancer referral centers in Rwanda. Oncologist 2015;20:780-8.

36 Price AJ, Ndom P, Atenguena E, et al. Cancer care challenges in developing countries. Cancer 2012;118:3627-35.

37 Sayed S, Ngugi AK, Mahoney MR, et al. Breast cancer knowledge, perceptions and practices in a rural community in coastal Kenya. BMC Public Health 2019;19:180.

38 Ukwenya AY, Yusufu LMD, Nmadu PT. Delayed treatment of symptomatic breast cancer: the experience from Kaduna, Nigeria. South Afr J Surg 2008;46:106-10.

39 Dereje N, Addissie A, Worku A, et al. Extent and predictors of delays in diagnosis of cervical cancer in Addis Ababa, Ethiopia: a population-based prospective study. JCO Global Oncology 2020;6:277-84.

40 Abu-Helalah MA, Alshraideh HA, Da'na Moh'd, Md Da'na, et al. Delay in presentation, diagnosis and treatment for colorectal cancer patients in Jordan. J Gastrointest Cancer 2016;47:36-46.

41 Gebremariam A, Addissie A, Worku A, et al. Time intervals experienced between first symptom recognition and pathologic diagnosis of breast cancer in Addis Ababa, Ethiopia: a crosssectional study. BMJ Open 2019;9:7

42 Olarewaju SO, Oyekunle EO, Bamiro AO. Effect of sociodemographic variables on patient and diagnostic delay of breast cancer at the Foremost health care institution in Nigeria. $J$ Glob Oncol 2019;5:8.

43 Salih AM, Alfaki MM, Alam-Elhuda DM, et al. Factors delaying presentation of Sudanese breast cancer patients: an analysis using Andersen's model. Asian Pac J Cancer Prev 2016;17:2105-10.

44 Sharma K, Costas A, Damuse R, et al. The Haiti breast cancer initiative: initial findings and analysis of Barriers-to-Care delaying patient presentation. J Oncol 2013;2013:1-6.

45 Maghous A, Rais F, Ahid S, et al. Factors influencing diagnosis delay of advanced breast cancer in Moroccan women. BMC Cancer 2016;16:356. 
46 Manir K, Mukhopadhyay A, Banerjee D. Breast cancer awareness among urban Indian women: an Internet survey. IOSR Journal of Dental and Medical Sciences 2017;16:88-93.

47 Sharp JW, Hippe DS, Nakigudde G, et al. Modifiable patient-related barriers and their association with breast cancer detection practices among Ugandan women without a diagnosis of breast cancer. PLOS One 2019;14:e0217938.

48 Al Qadire M, Aljezawi Ma'en, Al-Shdayfat N. Cancer awareness and barriers to seeking medical help among Syrian refugees in Jordan: a baseline study. J Canc Educ 2019;34:19-25.

49 Al Qadire M. Awareness of cancer signs and barriers to help seeking: a national survey. J Canc Educ 2018;33:1206-12.

50 Desalu OO, Fawibe AE, Sanya EO, et al. Lung cancer awareness and anticipated delay before seeking medical help in the middle-belt population of Nigeria. int $j$ tuberc lung dis 2016;20:560-6.

51 Freij M, Al Qadire M, Khadra M, et al. Awareness and knowledge of ovarian cancer symptoms and risk factors: a survey of Jordanian women. Clin Nurs Res 2018;27:826-40.

52 Grosse Frie K, Kamaté B, Traoré CB, et al. Factors associated with time to first healthcare visit, diagnosis and treatment, and their impact on survival among breast cancer patients in Mali. PLoS One 2018;13:13.

53 Zahid T, Hussain S, Siddiqui A. Health seeking behavior of oral cancer patients of low socioeconomic status: a cross sectional study in a tertiary care hospital of karachi. J Dow Univ Health Sci 2014;8:72-9.

54 Khan MA, Hanif S, lqbal S. Presentation delay in breast cancer patients and its association with sociodemographic factors in North Pakistan. Chin J Cancer Res 2015;27:288-93.

55 Stapleton JM, Mullan PB, Dey S, et al. Patient-mediated factors predicting early- and late-stage presentation of breast cancer in Egypt. Psychooncology 2011;20:532-7.

56 Foerster M, Anderson BO, McKenzie F, et al. Inequities in breast cancer treatment in sub-Saharan Africa: findings from a prospective multi-country observational study. Breast Cancer Res 2019;21:11.

57 Leng J, Ntekim Al, Ibraheem A, et al. Infrastructural challenges lead to delay of curative radiotherapy in Nigeria. JCO Glob Oncol 2020;6:269-76.

58 Tessler R, Gupta S, Pathak J, et al. Rectal bleeding and implications for surgical care in Nepal. J Surg Res 2015;197:12-17.

59 Okobia M, Bunker C, Okonofua F, et al. Knowledge, attitude and practice of Nigerian women towards breast cancer: a cross-sectional study. World J Surg Oncol 2006;4:11

60 Kishore J, Ahmad I, Kaur R, et al. Beliefs and perceptions about cancers among patients attending radiotherapy OPD in Delhi, India. Asian Pac J Cancer Prev 2008;9:155-8.

61 Hameed Khaliq I, Mahmood HZ, Sarfraz MD, et al. Pathways to care for patients in Pakistan experiencing signs or symptoms of breast cancer. The Breast 2019;46:40-7.

62 Agbokey F, Kudzawu E, Dzodzomenyo M, et al. Knowledge and health seeking behaviour of breast cancer patients in Ghana. Int $J$ Breast Cancer 2019;2019:1-9.

63 Asoogo C, Duma SE. Factors contributing to late breast cancer presentation for health care amongst women in Kumasi, Ghana. Curationis 2015;38.

64 Bonsu AB, Ncama BP. Recognizing and appraising symptoms of breast cancer as a reason for delayed presentation in Ghanaian women: a qualitative study. PLoS One 2019;14:21.

65 Fles R, Bos ACRK, et al. The role of Indonesian patients' health behaviors in delaying the diagnosis of nasopharyngeal carcinoma. BMC Public Health 2017;17:8.

66 Getachew S, Tesfaw A, Kaba M, et al. Perceived barriers to early diagnosis of breast cancer in South and southwestern Ethiopia: a qualitative study. BMC Womens Health 2020;20:8

67 Kumar A, Bhagabaty SM, Tripathy JP, et al. Delays in diagnosis and treatment of breast cancer and the pathways of care: a mixed methods study from a tertiary cancer centre in North East India. Asian Pac J Cancer Prev 2019;20:3711-21.

68 Deliana M, Suza DE, Tarigan R. Advanced stage cancer patients experience in seeking treatment in Medan, Indonesia. Open Access Maced J Med Sci 2019;7:2194-203.

69 Sanuade OA, Ayettey H, Hewlett S, et al. Understanding the causes of breast cancer treatment delays at a teaching hospital in Ghana. $J$ Health Psychol 2018;41:135910531881415.

70 Kohler RE, Gopal S, Miller AR, et al. A framework for improving early detection of breast cancer in sub-Saharan Africa: a qualitative study of help-seeking behaviors among Malawian women. Patient Educ Couns 2017;100:167-73.

71 Aziato L, Clegg-Lamptey JNA. Breast cancer diagnosis and factors influencing treatment decisions in Ghana. Health Care Women Int 2015;36:543-57.
72 Martei Y. Effect of Socio-Cultural beliefs on late stage presentation of breast cancer among Ghanaian women. Yale Medicine Thesis Digital Library 2011:1576.

73 Muthoni A, Miller AN. An Exploration of Rural and Urban Kenyan Women's Knowledge and Attitudes Regarding Breast Cancer and Breast Cancer Early Detection Measures. Health Care Women Int 2010:31:801-16.

74 Pruitt L, Mumuni T, Raikhel E, et al. Social barriers to diagnosis and treatment of breast cancer in patients presenting at a teaching hospital in Ibadan, Nigeria. Glob Public Health 2015;10:331-44.

75 Kaninjing E, Lopez I, Nguyen J, et al. Prostate cancer screening perception, beliefs, and practices among men in Bamenda, Cameroon. Am J Mens Health 2018;12:1463-72.

76 Gakunga R, Kinyanjui A, Ali Z, et al. Identifying barriers and facilitators to breast cancer early detection and subsequent treatment engagement in Kenya: a qualitative approach. Oncologist 2019;24:1549-56.

77 Iskandarsyah A, de Klerk C, Suardi DR, et al. Psychosocial and cultural reasons for delay in seeking help and nonadherence to treatment in Indonesian women with breast cancer: a qualitative study. Health Psychology 2014;33:214-21.

78 Meacham E, Orem J, Nakigudde G. Exploring stigma as a barrier to cancer service engagement with breast cancer survivors in Kampala, Uganda. Psychooncology 2016;25:1206-11.

79 Mwaka AD, Okello ES, Orach CG. Barriers to biomedical care and use of traditional medicines for treatment of cervical cancer: an exploratory qualitative study in northern $U$ ganda. Eur J Cancer Care 2015;24:503-13

80 Uddin N, Fateem E, Hablas A, et al. Public and professional educational needs for downstaging breast cancer in Egypt. J Canc Educ 2012;27:149-55.

81 Steiness HS, Villegas-Gold M, Parveen H, et al. Barriers to care for women with breast cancer symptoms in rural Bangladesh. Health Care Women Int 2018;39:536-54.

82 Basharat S, Shaikh BT, Rashid HU. Health seeking behaviour, delayed presentation and its impact among oral cancer patients in Pakistan: a retrospective qualitative study. BMC Health Serv Res 2019;19:1.

83 McEwan J, Underwood C, Corbex M. "Injustice! That Is the Cause" A Qualitative Study of the Social, Economic, and Structural Determinants of Late Diagnosis and Treatment of Breast Cancer in Egypt. Cancer Nurs 2014;37:468-75.

84 Dye TD, Bogale S, Hobden C, et al. Experience of initial symptoms of breast cancer and triggers for action in Ethiopia. Int $\mathrm{J}$ Breast Cancer 2012;2012:1-5.

85 Macleod U, Mitchell ED, Burgess C, et al. Risk factors for delayed presentation and referral of symptomatic cancer: evidence for common cancers. Br J Cancer 2009;101 Suppl 2:S92-101.

86 Balasooriya-Smeekens C, Walter FM, Scott S. The role of emotions in time to presentation for symptoms suggestive of cancer: a systematic literature review of quantitative studies. Psychooncology 2015;24:1594-604

87 Kummer S, Walter FM, Chilcot J, et al. Measures of psychosocial factors that may influence help-seeking behaviour in cancer: a systematic review of psychometric properties. J Health Psychol 2019;24:79-99.

88 Cancer Research UK. The cancer awareness measure (cam). Available: www.cancerresearchuk.org/health-professional/ awareness-and-prevention/the-cancer-awareness-measures-cam [Accessed 15 Sep 2020].

89 Simon AE, Forbes LJL, Boniface D, et al. An international measure of awareness and beliefs about cancer: development and testing of the ABC. BMJ Open 2012;2:e001758.

90 Neal RD, Nafees S, Pasterfield D, et al. Patient-Reported measurement of time to diagnosis in cancer: development of the cancer symptom interval measure (C-SIM) and randomised controlled trial of method of delivery. BMC Health Serv Res 2014;14:3

91 Ahmad F, Kabir SF, Purno NH, et al. A study with Bangladeshi women: seeking care for breast health. Health Care Women Int 2017;38:334-43.

92 El-Shinawi M, Youssef A, Alsara M, et al. Assessing the level of breast cancer awareness among recently diagnosed patients in Ain Shams university hospital. The Breast 2013;22:1210-4.

93 Mhaidat NM, Al-husein BA, Alzoubi KH, et al. Knowledge and awareness of colorectal cancer early warning signs and risk factors among university students in Jordan. J Canc Educ 2018;33:448-56.

94 Ströbele L, Kantelhardt EJ, Traoré Millogo TFD, et al. Prevalence of breast-related symptoms, health care seeking behaviour and diagnostic needs among women in Burkina Faso. BMC Public Health 2018;18:7. 